\title{
CD14 inhibition improves survival and attenuates cardiopulmonary dysfunction and thrombo-inflammation in a non-human primate model of Escherichia coli sepsis
}

Ravi S. Keshari ${ }^{{ }^{*}}$, Robert Silasi ${ }^{1^{\star}}$, Narcis I. Popescu ${ }^{2}$, Hala Chaaban ${ }^{3}$, Cristina Lupu ${ }^{1}$, Tom E. Mollnes $^{4,5,6 \#}$, Florea Lupu ${ }^{1,7 \#}$

${ }^{1}$ Cardiovascular Biology Research Program, Oklahoma Medical Research Foundation, Oklahoma City, OK 73104; ${ }^{2}$ Arthritis and Clinical Immunology Research Program, Oklahoma Medical Research Foundation, Oklahoma City, OK 73104; ${ }^{3}$ Department of Pediatrics, Neonatal and Perinatal Section, University of Oklahoma Health Sciences Center, Oklahoma City, OK; ${ }^{4}$ Department of Immunology, Oslo University Hospital, and University of Oslo, 0424 Oslo, Norway; ${ }^{5}$ Research Laboratory Nordland Hospital, K. G. Jebsen Thrombosis Research and Expertise Center, University of Tromsø, 8092 Bodo, Norway; ${ }^{6}$ Centre of Molecular Inflammation Research, Norwegian University of Science and Technology, 7491 Trondheim, Norway; and ${ }^{7}$ Departments of Cell Biology, Pathology and Internal Medicine, University of Oklahoma Health Sciences Center, Oklahoma City, OK.

${ }^{*}$ RSK and RS equally contributed.

\#TEM and FL jointly coordinated the study and are co-senior authors

Correspondence: Florea Lupu, Cardiovascular Biology Research Program, Oklahoma Medical Research Foundation, 825 NE 13th Street, Oklahoma City, OK 73104; E-mail: florea-lupu@omrf.org; Phone: (405) 2717462. 


\section{Abstract}

Gram-negative bacterial sepsis induces robust inflammation primarily via LPS signaling through TLR4, a process that involves the GPI-anchored co-receptor CD14 transferring LPS to the TLR4/MD-2 complex. Our group has shown that systemic inhibition of CD14 attenuates organ inflammation in a porcine model of $E$. coli sepsis. Here we investigated the effect of anti-CD14 antibody on thrombo-inflammation, including complement activation and hemostasis, as well as cell death/organ injury and mortality in a baboon model of lethal $E$. coli sepsis. Two experimental groups of 5 animals each were studied: (i) E. coli challenge; (ii) E. coli challenge plus anti-CD14 administered intravenously 30 minutes before E. coli. As compared to the control group, anti-CD14 reduced to different extents plasma cytokines (TNF, IFN- $\gamma, \mathrm{MCP}-1, \mathrm{IL}-1 \beta, \mathrm{IL}-8, \mathrm{IL}-1 \mathrm{RA})$ and prevented the robust complement activation induced by $E$. coli, as shown by C3b, C5a and C5b-9. The coagulation, fibrinolysis, cell death and organ function biomarkers were changed at varying levels. Most prominent was the strong decrease of PAI-1, accompanied by enhanced fibrinolysis in the anti-CD14 group. The treatment improved bacteria clearance, whereas LPS levels were similar in both groups. Importantly, 2 animals passed the 7-day end-point criteria (survivor), while 3 animals had prolonged survival compared to non-treated controls. Parameters that showed significant differences between survivors and non-survivors in the anti-CD14 group include leukocyte number, TAFI, HMGB1, creatinine and some cytokines. Our results highlight the crosstalk between Toll-like receptors, hemostasis and complement, and suggest a protective role of anti-CD14 treatment in sepsis. 


\section{Introduction}

Sepsis and accompanying systemic inflammatory response syndrome comprise a spectrum of clinical symptoms with a complex pathophysiology. Sepsis, and in particular septic shock represent major health problems and burden to the health care systems worldwide. Sepsis affects 18 million patients annually and results in 350,000 premature deaths in Europe and the US at a total cost of about $\$ 28$ billion. The incidence of sepsis is rising by approximately $1.5 \%$ per year. The morbidity is high and if progressing to septic shock the mortality can reach $30-70 \%(1-3)$. Sepsis is the most common cause of neonatal mortality being responsible for $30-50 \%$ of total neonatal deaths in developing countries each year (4). In addition to polymicrobial sepsis, the unimicrobial sepsis is equally shared by gram-negative and gram-positive cases $(5,6)$. Except for antibiotics and supportive care, there is no specific treatment for sepsis.

Even if antibiotics successfully kill the bacteria, the pathophysiology of sepsis leading to organ failure and in worst cases to death is driven by the host's own inflammatory response to microbes (7). If this response is forceful enough it will lead to an uncontrolled cytokine storm induced by the recognition systems of innate immunity, typically the plasma cascades of complement and coagulation, and the innate cells receptor systems, including Toll-like receptors (TLRs) and nucleotide oligomerization domain-like receptors. The joint activation of inflammation and the hemostatic system will lead to thrombo-inflammation, which when occurs intravascular, will progress to disseminated intravascular coagulation (DIC) and shock. At a certain stage "the point of no return" will be reached and no treatment will be efficient anymore.

TLRs are pattern recognition receptors present in nearly all mammalian cells and especially on cells important for innate immunity signaling such as dendritic cells, leukocytes and endothelial cells (8). TLRs are activated in the presence of microbes expressing or releasing pathogen associated molecular patterns (PAMP), or when damage associated molecular patterns (DAMP) are released from the host necrotic tissue. Upon activation, TLRs 
initiate an inflammatory pathway coordinated by the release of pro-inflammatory compounds such as cytokines..

During gram-negative sepsis, lipopolysaccharide (LPS) stimulates synthesis of proinflammatory cytokines through binding to the soluble LPS-binding protein (LBP), which transfers LPS to CD14 and TLR4/myeloid differentiation factor-2 (MD-2) complex $(9,10)$. In gram-positive sepsis, lipoproteins bind to TLR2, which also utilizes CD14 as co-receptor $(11,12)$. DAMPs interact with TLRs using CD14 as co-receptor, with a subsequent sterile response very similar to the PAMP-induced inflammation (13-15). Endogenous ligands for TLR4 that may contribute to signaling during sepsis include HMGB1, heat shock proteins, urate crystals and defensins (16). The TRL4/MD2 antagonist Eritoran (E5564) has been tried in human sepsis, but was stopped in a phase III trial due to lack of effect on survival (17). Inhibition of CD14 has been tested in rabbit $(18,19)$ and non-human primate models $(20)$, as well as in human volunteers (21-23). Beneficial effects were seen on the inflammatory response and cytokine storm. The use of anti-CD14 antibody in a mouse polymicrobial model (cecal ligation and puncture) protected against mortality (23), as did a conjugate between anti-CD14 and a coagulation FXla inhibitor (24), whereas no effect was seen in CD14 knock out mice (25). Anti-CD14 antibody efficiently protected against the cytokine storm in porcine E. coli sepsis (26) and increased survival in porcine polymicrobial sepsis when combined with a complement inhibitor (27). One single phase I trial has been performed in human sepsis using anti-CD14 (28), but follow-up studies are missing.

We have previously developed and characterized a gram-negative non-human primate model of sepsis by intravenous infusion of $E$. coli (29). In this model we have studied another branch of the innate immunity, namely the complement system, and showed that complement C3 inhibition decreased the inflammatory reaction, hemostatic dysfunction and prevented organ failure $(30,31)$, whereas C5 inhibition significantly improved survival in the LD100 model (32). The aim of the present study was to investigate the effects of blocking CD14 using an anti-CD14 antibody, on the pathophysiology and survival of E. coli sepsis. 


\section{Materials and Methods}

\section{Baboon model of $E$. coli sepsis}

This study was performed in compliance with the Animal Welfare Act, the Guide for the Care and Use of Laboratory Animals (33), and the NIH Office of Laboratory Animal Welfare and has received prior approvals from the Institutional Animal Care and Use Committees of both the Oklahoma Medical Research Foundation and the University of Oklahoma Health Sciences Center. Healthy Papio anubis baboons 3-4 years of age and 6-12 kg body weight, with hemoglobin greater than $10 \mathrm{mg} / \mathrm{dL}$ and WBC counts less than $12 \times 10^{9} / \mathrm{L}$ were randomly distributed between the control and treatment groups. The study included two experimental arms: (i) five animals were challenged with E. coli $\left(1-2 \times 10^{10} \mathrm{CFU} / \mathrm{kg}\right.$, LD100 dose, serotype B7-086a:K61; ATCC, Manassas, VA) through intravenous infusion (IV) over 2 hours; and (ii) five animals were treated with anti-CD14 monoclonal antibody (clone 23G4, ATCC, $3 \mathrm{mg} / \mathrm{kg}$ ) as a single IV bolus, 30 min before the challenge. The time before and after $\mathrm{n}$ hours of $E$. coli infusion is referred to as $T-n$ and $T+n$ hours, respectively. Animals were sedated with pentobarbital administered IV periodically to maintain a light level of anesthesia during the experimental procedure. The antibiotic gentamicin was given first as IV infusion ( $9 \mathrm{mg} / \mathrm{kg}, 1 \mathrm{~h})$ after completion of $E$. coli challenge $(T+2)$, then $4.5 \mathrm{mg} / \mathrm{kg} \mathrm{IM}$ at $\mathrm{T}+8$. Critical care monitoring was done as previously described (34). Core body temperature, oxygen saturation, mean systemic arterial pressure (MSAP), and heart and respiration rates were monitored with a Cardell Max-12 HD Duo monitor (Abaxis Veterinary Diagnostics, Union City, CA). Blood samples and physiological parameters were collected while the animal was under anesthesia, and the clinical condition was monitored during the whole duration of the study. After 7 days or when their clinical condition deteriorated, animals were humanely euthanized with Euthasol (50 mg/kg, IV).

\section{Bacteria count in the blood}

Blood bacteremia expressed as Colony forming units (CFU) was determined as described 


\section{Biochemical assays}

Blood urea nitrogen (BUN), creatinine, albumin, total protein and alanine aminotransferase (ALT) were measured by using a comprehensive diagnostic profile rotor on a VetScan VS2 (Abaxis Veterinary Diagnostics, Union City, CA) chemistry analyzer (35). Lactate in the blood was measured using Lactate Scout (EKF Diagnostics, San Antonio, TX).

\section{Immunoassays}

Plasma cytokines (TNF, IL1ß, IL6, IL8, IFNy, IL10, IL17, IL1RA, GM-CSF, and MCP1) were measured using the MILLIPLEX MAP Nonhuman Primate Cytokine Magnetic Bead Panel (EMD Millipore, Burlington, MA) as per the manufacturer's instructions. Plasma levels of inhibitory complexes of antithrombin (AT) with activated coagulation factors Xla, VIla and thrombin (FXla-AT, FVIla-AT and thrombin-AT [TAT]) were measured using sandwich ELISAs as described (34). Activated Protein C (APC) complexes with $\alpha 1$-antitrypsin were determined with a sandwich ELISA using affinity purified antibodies, sheep anti-human protein C (2 $\mathrm{\mu g} / \mathrm{mL}$; Affinity Biologicals, Ancaster, ON) for capture and biotin-conjugated goat anti-human a1-antitrypsin (1 $\mu \mathrm{g} / \mathrm{mL}$; Affinity Biologicals) for detection. For D-dimer, mouse monoclonal antibody clone DD1 (Novus Biologicals, Littleton, CO) was used for capture and affinity purified HRP-conjugated polyclonal sheep anti-human fibrinogen (Affinity Biologicals) was used as detection antibody. Fibrin(ogen) degradation products (FDP) were measured using the Thrombo-Wellcotest (ThermoFisher, Waltham, MA) rapid latex agglutination assay (30). For plasmin-antiplasmin (PAP) complexes, affinity purified goat anti-plasminogen (2 $\mu \mathrm{g} / \mathrm{mL}$, Affinity Biologicals) was used as capture antibody and HRP-conjugated goat polyclonal anti-antiplasmin antibody was used for detection. Thrombin-activatable fibrinolysis inhibitor (TAFI) was detected with a commercial ELISA kit from Affinity Biologicals. Soluble thrombomodulin (TM), tissue-type plasminogen activator (t-PA) and plasminogen activator 
inhibitor 1 (PAI-1), soluble CD14 (sCD14) and LBP were measured with DuoSet ELISA kits from R\&D (Minneapolis, MN). C3b and C5b-9 were measured as described (36). The ELISA kits for HMGB1 and citrullinated histone H3 (Cit H3) were from Tecan US, Inc. (Morrisville, NC) and Cayman Chemicals (Ann Arbor, MI), respectively. Nucleosomes were measured using an ELISA kit from Roche Diagnostics (Mannheim, Germany).

\section{LPS quantification in plasma}

Endotoxin level in plasma was quantified as described (37) with slight modifications. Plasma samples were diluted in pyrogen-free water and heated at $70^{\circ} \mathrm{C}$ for 10 minutes to inactivate plasma enzymes that may interfere with the assay. Pyrochrome reagent (Associates of Cape Cod [ACC], East Falmouth, MA) was reconstituted with $3.2 \mathrm{~mL}$ Glucashield buffer (ACC). 50 $\mu \mathrm{L}$ diluted plasma samples were mixed with $50 \mu \mathrm{L}$ Pyrochrome reagent and plate was read at $405 \mathrm{~nm}$ in the kinetic mode. Control Standard Endotoxin (ACC) was used as a standard.

\section{Myeloperoxidase activity assay}

Plasma level of myeloperoxidase (MPO) was determined using Fluoro MPO detection kit (Cell Technology, Fremont, CA) (35).

\section{Clotting time tests}

Activated partial thromboplastin time (APTT) and prothrombin time (PT) were measured as described (30). Functional fibrinogen was determined using a clotting based assay (38).

\section{Microscopy}

Tissues fixed in formalin and embedded in paraffin were used for hematoxylin-eosin and phosphotungstic acid hematoxylin staining to reveal the general tissue morphology and fibrin deposits (35).

\section{Statistical analysis}


Statistical analysis was performed using Prism (GraphPad Software 7.0b). Values are given as mean \pm SEM. Comparisons between two groups for each time point were performed using multiple $\mathrm{t}$ tests with correction for multiple comparisons using the Holm-Sidak method.. Area under the curve (AUC) values were calculated for the treated and non-treated groups for the time intervals $0-24$ hours, and for the survivors vs. non-survivors in the anti-CD14 treated group for the time intervals $0-72$ hours. Results were considered significant at $p<0.05$ $\left({ }^{*} p<0.05,{ }^{* *} p<0.01,{ }^{* * *} p<0.001,{ }^{* * *} p<0.0001\right)$. Comparison of survival data was done using log-rank Mantel-Cox test.

\section{Results}

\section{Cardiopulmonary function and mortality}

MSAP was partly preserved and more stable throughout the 8 hours observation period in the treated group compared to the untreated, which showed a marked fall in the early phase (AUC; $p=0.0067$ ) (Fig. 1A). Heart rate was $\sim 10 \%$ higher and stable in the treated group compared to controls (AUC; $\mathrm{p}<0.0001$ ) (Fig. 1B). The treatment also improved pulmonary function, reflected by the slightly increased respiratory rate (Fig. 1C) and preserved oxygen saturation (AUC; $p=0.001$ ) (Fig. 1D). The core body temperature increased to a lesser extent in the treated group than in controls (AUC; $p=0.0008$ ) (Fig. 1E).

The survival was significantly increased in the treated group compared to the untreated $(p=0.0018)($ Fig. 1F). The mean time to death reached 74 hours in three treated animals compared to 30 hours in the untreated. All control animals died within 24-36 hours, whereas two of the treated animals survived and recovered (7 days observation).

\section{Plasma proteins and cascade systems}

Plasma proteins. Decrease in total protein (Fig. 2A) and plasma albumin (Fig. 2B), reflecting the degree of capillary leakage, was $\sim 20 \%$ less pronounced in the treated group 
than in the untreated during the first 8 hours and the total protein completely recovered in the survivors.

Complement. Activation of the complement system was detected in plasma by measuring the $\mathrm{C} 3$ activation product $\mathrm{C} 3 \mathrm{~b}$ (Fig. $2 \mathrm{C}$ ), $\mathrm{C} 5$ activation product $\mathrm{C} 5 \mathrm{a}$ (Fig. 2D), and the soluble terminal sC5b-9 complex (Fig. 2E). A substantial increase was observed for all three activation markers in the LD100 control group, and the treatment markedly reduced them: C3b by $50 \%$ (AUC; $p=0.0066)$, C5a by $40 \%(A \cup C ; p=0.03$ ) and $\mathrm{sC} 5 \mathrm{~b}-9$ by $45 \%$ (AUC; $\mathrm{p}=0.017$ ) (Fig. 2, C-E). The values were similar between survivors and non-surviving animals (not shown).

Coagulation. There were no differences between groups when evaluated by the traditional APTT (Fig. 3A) and PT (Fig. 3B), although the two survivors in the treated group showed $\sim 20 \%$ decrease of APTT vs. non-surviving animals (not shown) The effect of treatment differed substantially, however, between the intrinsic and extrinsic pathways, as measured by the complexes FXla-AT and FVIla-AT, respectively. No effect was seen on the intrinsic pathway (Fig. 3C). FVIla-AT was reduced by $57 \%$ (AUC; $p=0.0035$ ) (Fig. 3D) in the treated group compared to the untreated, and the two treated survivors showed $\sim 30 \%$ lower levels than the three non-survivors (not shown). TAT (thrombin-antithrombin) complexes (Fig. 3E) and APC-a1-antitrypsin complexes (Fig. 3F) were, however, similar in both groups though slightly lower in the treated, consistent with the non-inhibited activation of the intrinsic pathway overwhelming the beneficial effect of the treatment on the extrinsic system. Fibrinogen consumption, the last step of coagulation, was similar in the two groups during the first 8 hours and recovered completely by 48 hours in treated animals (Fig. 3G).

Fibrinolysis. CD14 inhibition had a profound effect on fibrinolysis (Fig. 4). Formation of FDP was reduced 2.5 -fold in the treated group compared to controls during the first 8 hours (AUC; $p=0.013$ ) and reversed completely in survivors (Fig. 4A). tPA release was delayed in the treated group compared to the untreated but reached the peak at 8 hours and remained stable high until 72 hours (AUC; $p=0.025$ ) (Fig. 4B). The treatment prevented by $90 \%$ the marked increase in PAI-1 observed in the controls (AUC; $p=0.0001$ ) during the first 
24 hours (Fig. 4C). PAP complexes increased 3-times in the treated group vs. untreated (AUC; $p=0.0015$ ) (Fig. 4D). Similarly, D-dimer was $\sim 2$-fold higher in the treated group (AUC; $\mathrm{p}=0.0038)$ (Fig. 4E). TAFI was marginally lower in the treated group than in controls (Fig. 4F). In contrast to the other parameters, TAFI levels were highly significant lower for survivors vs. non-survivors, treated or not (AUC; $p=0.006)$ (Suppl. Fig. 1).

\section{Cytokines}

Ten cytokines that substantially increased in the LD100 controls displayed four different patterns of response to treatment (Fig. 5). A substantial reduction was seen for TNF (70\%; AUC; $p=0.0064)$ (Fig. 5A), IFNy (53\%; AUC; p=0.014) (Fig. 5B), and IL-1RA (20\%; AUC; ns) (Fig. 5C). A clearly delayed increase without significant differences in peak values was seen for IL-1 $\beta$ (Fig. 5D), IL-8 (Fig. 5E) and MCP-1 (Fig. 5F). The treatment produced a slight reduction of IL-17a (Fig. 5G) and GM-CSF (Fig. 5H). No reduction, but rather slight increase in peak values was observed for IL-6 (Fig. 5I) and IL-10 (Fig. 5J). Within the treated group, there was a clear difference between survivors and non-survivors (Suppl. Fig. 2). This was consistently seen for all 10 cytokines, but the differences were most extensive for IFNY $(A \cup C ; p=0.012)(B), I L-1 \beta(A \cup C ; p=0.034)(D), I L-8(A \cup C ; p=0.04)(E)$ and IL-6 (AUC; $p=0.066)(I)$, where treated survivors showed very little increase if any. Although the numbers are small, these results could explain why the pooled data for the treated group were relatively similar to the non-treated.

\section{Blood cells}

White blood cells (WBC) numbers fell abruptly and similarly in both groups up to 8 hours and recovered fully in the treated group by 48 hours (Fig. 6A), although the treated non-survivors' numbers stayed $\sim 45 \%$ lower till 72 hours (AUC; $p=0.0003$ ) (Suppl. Fig. $3 A$ ). MPO, used as marker of neutrophil activation, was reduced by $35 \%$ in the treated group compared to controls during the first 24 hours (AUC; $p=0.048$ ) (Fig. 6B) and recovered in the survivors. Platelet numbers decreased rapidly and similarly in both groups and recovered in 
the surviving animals (Fig. 6C). Red blood cells (RBC) were stable for 8 hours, where after their numbers fell without differences between the groups (Fig. 6D). Hematocrit and hemoglobin behaved identical to RBC counts (not shown).

\section{Cell death}

Markers of cell death included Cit $\mathrm{H} 3$, which is released from neutrophil extracellular traps, nucleosomes containing DNA and histones, and HMGB1 released by necrosis (Fig. 7). Cit $\mathrm{H} 3$ increased identically in the two groups until 24 hours and recovered in the survivors (Fig. 7A). However, non-survivors in the treated group had 2-times higher levels than survivors up to 72 hours (AUC; $p=0.025$ ) (not shown). Nucleosomes increased 2 -fold in the treated group vs. untreated until 24 hours (AUC; $p<0.0001$ ) (Fig. 7B). Peak release of HMGB1 was marginally lower in the pooled treated group vs. controls (Fig. 7C), but values were significantly different (AUC; $p=0.017$ ) in the treated survivors vs. non-survivors. (Suppl. Fig. 3B).

\section{Organ function and pathology}

ALT (alanine aminotransferase), reflecting liver function was slightly reduced during the first 24 hours in the treated animals as compared to LD100 controls (AUC; $p=0.051$ ) and gradually recovered (Fig. $8 \mathrm{~A}$ ). The difference between survivors and non-survivors in the treated group was significant from 8-72 hours (AUC; $p=0.048$ ) (Suppl. Fig. 3C). The kidney function marker creatinine was reduced in the treated group by $30 \%$ as compared with the untreated during the first 24 hours (AUC; $p=0.01$ ) (Fig. 8B). For the 24-72 hours interval, treated non-survivors displayed $\sim 2$-fold higher values than the survivors (AUC; $p=0.017$ ) (Suppl. Fig. 3D). Lactate values, reflecting tissue hypoxia, were $50 \%$ reduced in the treated animals compared to controls, in particular after 8-24 hours (AUC; $p=0.0001$ ) (Fig. 8C).

Histopathological evaluation of the organs post mortem cannot be temporally compared due to the differences to the time of death but gave important information nonetheless (Fig. 9). The pathology severity score of the kidney, spleen, lung and liver generally showed little 
difference between the two groups (Fig. 9, A-D). Nevertheless, some parameters did reflect potential improvement in the treated group: kidney tubular necrosis, follicular necrosis and medullar congestion in the spleen, capillary leakage in the lung and liver congestion. A marked and significant protection by the treatment was observed for the adrenals (Fig. 9E and Fig. 10, A-D). Microthrombosis, cortical necrosis and cortical hemorrhage were not observed in the treated animals, and leukocyte infiltration and cortical congestion were $\sim 50 \%$ reduced. Representative images of adrenals histopathology indicating important protective effects of the anti-CD14 antibody treatment are shown in Fig. 10.

\section{LPS, LBP, sCD14 and bacteria}

LPS. The abrupt increase in LPS by 2 hours was similar in non-treated controls and treated non-survivors (Fig. 11A). Notably, treated survivors had significantly lower LPS (AUC; $p=0.008$ ) than non-survivors (Suppl. Fig. 3E),.

LBP. A marked increase in LBP was seen by 24 hours, similar in both groups (Fig. 11B). LBP level fell in the treated animals, but was still elevated after 7 days.

Soluble CD14 (sCD14). The membrane receptor CD14 also exists as the soluble form sCD14 in plasma. SCD14 increased markedly in the treated animals after the anti-CD14 antibody was given, before infusion of E. coli started (Fig. 11C). The levels stayed stable high for 24 hours but recovered completely by 48 hours in the treated survivors whereas staying very high for non-survivors till 72 hours (Suppl. Fig. 3F). sCD14 increased modestly in the control animals by 8 hours. The increase of sCD14 in the treated group was 20 -fold higher than in the non-treated during the first 8 hours (AUC; $p=0.002$ ). In order to avoid any false effect due to interference in the SCD14 assay, in vitro experiments were performed by adding anti-CD14 antibody to native baboon plasma. No increase was observed, rather a modest decline as would be expected since anti-CD14 will cover some antigenic sites on the molecule (optical density from baseline 0.8 to 0.6 for the highest dose). 
E. coli count. Bacterial count measured as CFU fell abruptly and similarly in both groups during the first 4 hours (Fig. 11D). The decrease in CFU from 4 to 24 hours was almost 10-times more pronounced in the treated group than in controls ( $A \cup C ; p=0.014$ ).

\section{Discussion}

The present data show, to the best of our knowledge, for the first time the effects of inhibiting CD14 in a non-human primate model of sepsis using whole $E$. coli bacteria. The data support the idea that CD14 is a multifunctional protein cross-talking with several branches of innate immunity and hemostasis, placing it as a key molecule in thromboinflammation. Most importantly, inhibition of CD14 improved cardiopulmonary function and reduced the mortality. The mechanisms behind these effects seem to involve robust inhibition of the complement, with accompanying reduction of capillary leakage and strong activation of fibrinolysis. The effect on inflammation varied, with efficient inhibition of several key cytokines, but with a surprisingly lack of effect on IL-6. The effects on coagulation and cell death markers were modest except for HMGB1, and a remarkable increase in sCD14 was observed immediately after antibody infusion. Surprisingly, bacteria clearance was enhanced rather than inhibited.

There are more than 200 putative mediators of sepsis and there have been over 70 well-designed clinical trials to test the effect of manipulation of a number of these mediators. The results have been largely disappointing reflecting the idea that targeting single downstream regulators is not sufficient to resolve such a complex pathology $(39,40)$. Clinical trials using inhibitors of TNF, IL-1 $\beta$ and IL-6 have all failed. The only FDA-proved drug for sepsis treatment in clinical use for some years (APC, Xigris $®$ ), was withdrawn from the market due to lack of documented effects (41). The promising clinical program with the TLR4/MD2 inhibitor eritoran (E5564) was closed, due to lack of effect on survival (17). Novel approaches are urgently required given that all clinical trials conducted to date have failed (42). In the ex vivo human whole blood model using bacteria, we demonstrated that inhibition of single downstream cytokines TNF or IL-1 $\beta$ had no effect on the inflammatory response 
(43). The selective TLR4 inhibitor eritoran could not compete with anti-CD14 in the same model when using whole bacteria, whereas inhibition of purified LPS-induced cytokines was similar for CD14 and eritoran (44). This underscores the need for defining targets with a broad spectrum of functions.

Ten different human TLRs identified so far recognize distinct PAMP and DAMP signals (45) and initiate immune responses to the growing list of endogenous DAMPs and exogenous PAMPs present in sepsis. TLRs interact with many accessory proteins and cofactors to elicit intracellular signaling and pro-inflammatory gene transcription and cytokine release. PAMPs and/or DAMPs bind to CD14 and induce its conformational change and subsequent activation. The activated form of CD14 interacts with TLR4 and TLR2 and triggers downstream events that lead to the inflammatory response and release of innumerable mediators including pro-inflammatory cytokines. CD14 acts as a key orchestrator of the innate immune system. CD14 is a 375 -amino-acid glycoprotein comprising multiple leucine-rich repeats and is present both as GPI-anchored membrane protein and soluble (sCD14) form. CD14 can bind multiple ligands including LPS, peptidoglycan, polyl:C, and DNA. Once bound, CD14 chaperones these pathogenic molecules to the correct TLR. CD14 is also a co-receptor for TLR3, TLR7 and TLR9, at least in mice $(46,47)$. This places CD14 as an outmost interesting bottleneck integrator molecule for innate immunity recognition and a promising target for preventing TLR-induced inflammation.

Several of the effects observed for CD14 inhibition in our study were surprising, both on the beneficial side and on "the lack of effect" side. Overall, the treatment had beneficial effects on the cardiopulmonary physiology and, most important, on the mortality. The better preservation of blood pressure could be due to the adrenals, whose adrenomedullin production prevents the transition from the hyperdynamic to the hypodynamic phases of sepsis (48). Improvement of microcirculation, as indicated by less capillary leakage in the treatment group may have contributed to the better pulmonary function with higher oxygen saturation and could also explain the lower lactate values. However, the differences in organ 
function parameters for most of the organs were minor between the two groups. For the kidneys, organ function cannot be evaluated during this first phase of sepsis, since kidney failure occurs after 3-5 days. One of the most interesting and surprising findings was the effect of anti-CD14 antibody on complement activation, whereby it completely abolished the formation of $\mathrm{C} 5 \mathrm{a}$, , a highly pro-inflammatory mediator that contributes to septic shock. Inhibition of C5a increased survival in mouse studies (49). We recently showed that a small molecule (Ra101295) that prevents C5 cleavage increased survival to $100 \%$ in the current baboon E. coli model, most likely through blocking both C5a and C5b-9 generation (32). Inhibition of C5a reduces capillary leakage $(50,51)$. The mechanism of anti-CD14 inhibition of complement activation is uncertain and difficult to explain through direct effects. More probably, this is the result of the intensive cross-talk between complement and the TLR system (52). We have previously shown that the combined inhibition of complement, either C3 or C5, and CD14 had both additive and synergistic effects on the inflammatory response $(53,54)$. We suggest that the substantial inhibition of complement seen in the present study is a main reason for the beneficial effects on pathophysiology and prognosis. However, the direct link between CD14 and activation of complement remains to be elucidated.

The effect on coagulation of CD14 inhibition was limited to decreased FVIladependent activation of the extrinsic pathway. Overall the coagulation was not reduced as measured by fibrinogen consumption, probably due to the massive activation of the intrinsic system, which was not counteracted by the treatment, except for the two surviving animals. In contrast, the fibrinolytic markers were consistently changed in a pro-fibrinolytic manner, underscored by the extensive down-regulation of PAI-1, consistent with TNF being important for PAI-1 induction (55), and of TAFI. The change of the hemostatic balance toward fibrinolysis might protect against thrombosis, as was observed in the adrenals, and thus partly prevent DIC. No bleeding was observed as consequence of the increased fibrinolysis.

Very interesting observations appeared when we differentiated between the nonsurvivors and survivors within the treated group. For many of the parameters measured, there were significant differences between the two animals that survived 7 days and 
recovered fully, and the three lesser responders that died by 76 hours. This explains why pooled data for the treated group were relatively similar to the non-treated. It also underscores the necessity of finding biomarkers that could predict surviving/non-surviving outcome.

A remarkable increase in the LPS-binding proteins LBP and SCD14 was observed. LBP increased to the same extent in both groups after 8 hours and was, thus, dependent on E. coli-mediated mechanisms. In contrast, SCD14 increased about 20 -fold above baseline as a result of anti-CD14 antibody infusion, as this happened before $E$. coli infusion. The reason for this is uncertain, but most likely due to shedding of the constitutive cellular CD14 since its appearance was immediate, with cleavage of the phosphatidyl inositol anchor as the most likely explanation. Interference in the immunoassay for detection of SCD14 was excluded by in vitro experiments where anti-CD14 was added to baboon plasma, where the modest reduction in the signal observed is consistent with anti-CD14 covering some of the epitopes detected by the assay. The increase in SCD14 might have influenced the effects of antiCD14 negatively, i.e. it could explain the lack of effect on IL-6 and other cytokines, which normally should be markedly reduced, as we observed when anti-CD14 was used in a pig model of E. coli sepsis (26) and in a mouse model of polymicrobial sepsis (56). Implications of the increased SCD14 in the current study could be several. Since anti-CD14 antibody can bind both the soluble and the membrane bound CD14, there could be a competition between the soluble and membrane forms, leaving a portion of the membrane CD14 free and not inhibited by the antibody due to lack of excess anti-CD14. Thereby the blocking effect of cell signaling could be reduced. A second and important issue is that SCD14 can be taken up by endothelial cells when activated, since the endothelial cells express TLR4, but only limited amount of membrane CD14 (57). Thus, if not the whole pool of SCD14 is neutralized by the antibody for the same reason as for the cellular CD14, sCD14 can bind to endothelial cells and make the TLR/MD-2/CD14 receptor complex active $(58,59)$. The importance of this mechanism in our model is uncertain since anti-CD14 reduced capillary damage as 
evaluated by capillary leakage. However, other effects on the endothelial cells cannot be excluded.

Finally, an interesting observation was that CD14 inhibition increased bacterial killing instead of the expected decrease. Thus, CD14 is not a prerequisite for protection against $E$. coli bacteria at least not in our model, underscoring the redundancy of innate immunity in host defense. There seems to be no risk of reducing the CD14 part in host defense, at least for sepsis induced by E. coli.

In conclusion, despite the limitation of animals number to five in each group due to animal welfare and resource reasons, the data are robust and consistent and suggest that CD14 inhibition in E. coli sepsis has several benefits and could be a therapeutic option, although the effect of various anti-CD14 neutralization reagents should be compared in more detail to optimize the effect on soluble versus membrane bound CD14.

\section{Acknowledgements}

The authors thank Dr. Fletcher Taylor and Dr. Gary Kinasewitz for helpful discussions. This work was supported by grants from The Norwegian Council on Cardiovascular Disease (NCCD-2016 [T.E.M]) and The Odd Fellow Foundation (OFF-2015 [T.E.M.]); National Institutes of Health, National Institute of General Medical Sciences (GM116184 [F.L.], GM121601 [F.L.], GM12275 [F.L.] and P30GM114731 [F.L.]) and National Institute of Allergy and Infectious Diseases (U19AI062629 [F.L.]).

\section{Authorship}

Contribution: R.S., R.S.K., and F.L. performed animal experiments; R.S., R.S.K., and C.L. performed assays; R.S., R.S.K., C.L., T.E.M. and F.L. analyzed data; T.E.M. and F.L. designed and supervised the study and wrote the manuscript; C.L., R.S. and R.S.K. contributed to writing of various sections; CL provided critical revision of the manuscript. All authors read and approved the manuscript. 


\section{Conflict of interest disclosure}

The authors declare no competing financial interests.

ORCID profiles: RSK, 0000-0002-4177-9095; RS, 0000-0001-9590-6160; CL, 0000-00018619-0893; FL, 0000-0003-1249-9278. TEM, 0000-0002-5785-802X. 


\section{References}

1. Riedemann, N. C., Guo, R. F., and Ward, P. A. (2003) The enigma of sepsis. J. Clin. Invest 112, 460-467

2. Riedemann, N. C., Guo, R. F., and Ward, P. A. (2003) Novel strategies for the treatment of sepsis. Nat. Med 9, 517-524

3. Oberholzer, A., Oberholzer, C., and Moldawer, L. L. (2001) Sepsis syndromes: understanding the role of innate and acquired immunity. Shock 16, 83-96

4. Kutko, M. C., Calarco, M. P., Flaherty, M. B., Helmrich, R. F., Ushay, H. M., Pon, S., and Greenwald, B. M. (2003) Mortality rates in pediatric septic shock with and without multiple organ system failure. Pediatr Crit Care Med 4, 333-337

5. Levy, M. M., Artigas, A., Phillips, G. S., Rhodes, A., Beale, R., Osborn, T., Vincent, J. L., Townsend, S., Lemeshow, S., and Dellinger, R. P. (2012) Outcomes of the Surviving Sepsis Campaign in intensive care units in the USA and Europe: a prospective cohort study. Lancet Infect Dis 12, 919-924

6. Ranieri, V. M., Thompson, B. T., Barie, P. S., Dhainaut, J. F., Douglas, I. S., Finter, S., and Group, P.-S. S. (2012) Drotrecogin alfa (activated) in adults with septic shock. N Engl J Med 366, 2055-2064

7. van der Poll, T., van de Veerdonk, F. L., Scicluna, B. P., and Netea, M. G. (2017) The immunopathology of sepsis and potential therapeutic targets. Nat Rev Immunol

8. Vallejo, J. G. (2011) Role of toll-like receptors in cardiovascular diseases. Clin. Sci. (Lond) 121, 1-10

9. Heumann, D., and Roger, T. (2002) Initial responses to endotoxins and Gramnegative bacteria. Clin Chim. Acta 323, 59-72

10. Dobrovolskaia, M. A., and Vogel, S. N. (2002) Toll receptors, CD14, and macrophage activation and deactivation by LPS. Microbes. Infect 4, 903-914

11. Nilsen, N. J., Deininger, S., Nonstad, U., Skjeldal, F., Husebye, H., Rodionov, D., von, A. S., Hartung, T., Lien, E., Bakke, O., and Espevik, T. (2008) Cellular trafficking of 
lipoteichoic acid and Toll-like receptor 2 in relation to signaling; role of CD14 and CD36. J Leukoc. Biol 84, 280-291

12. Janot, L., Secher, T., Torres, D., Maillet, I., Pfeilschifter, J., Quesniaux, V. F., Landmann, R., Ryffel, B., and Erard, F. (2008) CD14 Works with Toll-Like Receptor 2 to Contribute to Recognition and Control of Listeria monocytogenes Infection. J Infect. Dis $198,115-124$

13. Abraham, E. (2009) Unraveling the role of high mobility group box protein 1 in severe trauma. Crit Care 13, 1004

14. McGhan, L. J., and Jaroszewski, D. E. (2011) The role of toll-like receptor-4 in the development of multi-organ failure following traumatic haemorrhagic shock and resuscitation. Injury $\mathbf{4 3}, 129-136$

15. Hirsiger, S., Simmen, H. P., Werner, C. M., Wanner, G. A., and Rittirsch, D. (2012) Danger signals activating the immune response after trauma. Mediators. Inflamm 2012, 315941

16. Yu, L., Wang, L., and Chen, S. (2010) Endogenous toll-like receptor ligands and their biological significance. J Cell Mol Med 14, 2592-2603

17. Opal, S. M., Laterre, P. F., Francois, B., Larosa, S. P., Angus, D. C., Mira, J. P., Wittebole, X., Dugernier, T., Perrotin, D., Tidswell, M., Jauregui, L., Krell, K., Pachl, J., Takahashi, T., Peckelsen, C., Cordasco, E., Chang, C. S., Oeyen, S., Aikawa, N., Maruyama, T., Schein, R., Kalil, A. C., Van, N. M., Lynn, M., Rossignol, D. P., Gogate, J., Roberts, M. B., Wheeler, J. L., and Vincent, J. L. (2013) Effect of eritoran, an antagonist of MD2-TLR4, on mortality in patients with severe sepsis: the ACCESS randomized trial. JAMA 309, 1154-1162

18. Schimke, J., Mathison, J., Morgiewicz, J., and Ulevitch, R. J. (1998) Anti-CD14 mAb treatment provides therapeutic benefit after in vivo exposure to endotoxin. Proc. Natl. Acad. Sci. U. S. A 95, 13875-13880 
19. Nakamura, M., Takeuchi, T., Shirakawa, K., and Furusako, S. (2017) Anti-human CD14 monoclonal antibody improves survival following sepsis induced by endotoxin, but not following polymicrobial infection. Eur J Pharmacol

20. Leturcq, D. J., Moriarty, A. M., Talbott, G., Winn, R. K., Martin, T. R., and Ulevitch, R. J. (1996) Antibodies against CD14 protect primates from endotoxin-induced shock. $J$ Clin. Invest 98, 1533-1538

21. Olszyna, D. P., Verbon, A., Pribble, J. P., Turner, T., Axtelle, T., van Deventer, S. J., and van der, P. T. (2003) Effect of IC14, an anti-CD14 antibody, on plasma and cellassociated chemokines during human endotoxemia. Eur. Cytokine Netw 14, 158-162

22. Verbon, A., Meijers, J. C., Spek, C. A., Hack, C. E., Pribble, J. P., Turner, T., Dekkers, P. E., Axtelle, T., Levi, M., van Deventer, S. J., Reitsma, P. H., and van der, P. T. (2003) Effects of IC14, an anti-CD14 antibody, on coagulation and fibrinolysis during low-grade endotoxemia in humans. $J$ Infect. Dis 187, 55-61

23. Daubeuf, B., Mathison, J., Spiller, S., Hugues, S., Herren, S., Ferlin, W., KoscoVilbois, M., Wagner, H., Kirschning, C. J., Ulevitch, R., and Elson, G. (2007) TLR4/MD-2 Monoclonal Antibody Therapy Affords Protection in Experimental Models of Septic Shock. The Journal of Immunology 179, 6107-6114

24. Nakamura, M., Takeuchi, T., Kawahara, T., Hirose, J., Nakayama, K., Hosaka, Y., and Furusako, S. (2017) Simultaneous targeting of CD14 and factor Xla by a fusion protein consisting of an anti-CD14 antibody and the modified second domain of bikunin improves survival in rabbit sepsis models. Eur $\mathrm{J}$ Pharmacol

25. Ebong, S. J., Goyert, S. M., Nemzek, J. A., Kim, J., Bolgos, G. L., and Remick, D. G. (2001) Critical role of CD14 for production of proinflammatory cytokines and cytokine inhibitors during sepsis with failure to alter morbidity or mortality. Infect. Immun 69, 2099-2106

26. Thorgersen, E. B., Hellerud, B. C., Nielsen, E. W., Barratt-Due, A., Fure, H., Lindstad, J. K., Pharo, A., Fosse, E., Tonnessen, T. I., Johansen, H. T., Castellheim, A., and 
Mollnes, T. E. (2009) CD14 inhibition efficiently attenuates early inflammatory and hemostatic responses in Escherichia coli sepsis in pigs. FASEB $J$ 24, 712-722

27. Skjeflo, E. W., Sagatun, C., Dybwik, K., Aam, S., Urving, S. H., Nunn, M. A., Fure, H., Lau, C., Brekke, O. L., Huber-Lang, M., Espevik, T., Barratt-Due, A., Nielsen, E. W., and Mollnes, T. E. (2015) Combined inhibition of complement and CD14 improved outcome in porcine polymicrobial sepsis. Crit Care 19, 415

28. Reinhart, K., Gluck, T., Ligtenberg, J., Tschaikowsky, K., Bruining, A., Bakker, J., Opal, S., Moldawer, L. L., Axtelle, T., Turner, T., Souza, S., and Pribble, J. (2004) CD14 receptor occupancy in severe sepsis: results of a phase I clinical trial with a recombinant chimeric CD14 monoclonal antibody (IC14). Crit Care Med 32, 11001108

29. Taylor, F. B., Jr., Kinasewitz, G. T., and Lupu, F. (2011) Pathophysiology, staging and therapy of severe sepsis in baboon models. J Cell Mol. Med

30. Silasi-Mansat, R., Zhu, H., Popescu, N. I., Peer, G., Sfyroera, G., Magotti, P., Ivanciu, L., Lupu, C., Mollnes, T. E., Taylor, F. B., Kinasewitz, G., Lambris, J. D., and Lupu, F. (2010) Complement inhibition decreases the procoagulant response and confers organ protection in a baboon model of Escherichia coli sepsis. Blood 116, 1002-1010

31. Lupu, F., Keshari, R. S., Lambris, J. D., and Mark, C. K. (2014) Crosstalk between the coagulation and complement systems in sepsis. Thromb. Res 133 Suppl 1, S28-S31

32. Keshari, R. S., Silasi, R., Popescu, N. I., Patel, M. M., Chaaban, H., Lupu, C., Coggeshall, K. M., Mollnes, T. E., DeMarco, S. J., and Lupu, F. (2017) Inhibition of complement C5 protects against organ failure and reduces mortality in a baboon model of Escherichia coli sepsis. Proc Natl Acad Sci U S A

33. Council, N. R. (2011) Guide for the Care and Use of Laboratory Animals: Eighth Edition, The National Academies Press, Washington, DC

34. Silasi, R., Keshari, R. S., Lupu, C., Van Rensburg, W. J., Chaaban, H., Regmi, G., Shamanaev, A., Shatzel, J. J., Puy, C., Lorentz, C. U., Tucker, E. I., Gailani, D., Gruber, A., McCarty, O. J. T., and Lupu, F. (2019) Inhibition of contact-mediated 
activation of factor $\mathrm{XI}$ protects baboons against $\mathrm{S}$ aureus-induced organ damage and death. Blood Adv 3, 658-669

35. Keshari, R. S., Silasi, R., Popescu, N. I., Patel, M. M., Chaaban, H., Lupu, C., Coggeshall, K. M., Mollnes, T. E., DeMarco, S. J., and Lupu, F. (2017) Inhibition of complement C5 protects against organ failure and reduces mortality in a baboon model of Escherichia coli sepsis. Proc Natl Acad Sci U S A 114, E6390-E6399

36. Keshari, R. S., Silasi, R., Popescu, N. I., Patel, M. M., Chaaban, H., Lupu, C., Coggeshall, K. M., Mollnes, T. E., DeMarco, S. J., and Lupu, F. (2017) Inhibition of complement C5 protects against organ failure and reduces mortality in a baboon model of Escherichia coli sepsis. Proc Natl Acad Sci U S A 114, E6390-E6399

37. Thorgersen, E. B., Pischke, S. E., Barratt-Due, A., Fure, H., Lindstad, J. K., Pharo, A., Hellerud, B. C., and Mollnes, T. E. (2013) Systemic CD14 inhibition attenuates organ inflammation in porcine Escherichia coli sepsis. Infect Immun 81, 3173-3181

38. Taylor, F. B., Jr., Stearns-Kurosawa, D. J., Kurosawa, S., Ferrell, G., Chang, A. C., Laszik, Z., Kosanke, S., Peer, G., and Esmon, C. T. (2000) The endothelial cell protein C receptor aids in host defense against Escherichia coli sepsis. Blood 95, $1680-1686$

39. Hotchkiss, R. S., and Karl, I. E. (2003) The pathophysiology and treatment of sepsis. N. Engl. J. Med 348, 138-150

40. Marshall, J. C. (2003) Such stuff as dreams are made on: mediator-directed therapy in sepsis. Nat. Rev. Drug Discov 2, 391-405

41. Williams, S. C. (2012) After Xigris, researchers look to new targets to combat sepsis. Nat Med 18, 1001

42. Editorial. (2012) Focus on sepsis. Nat Med 18, 997

43. Barratt-Due, A., Thorgersen, E. B., Lindstad, J. K., Pharo, A., Brekke, O. L., Christiansen, D., Lambris, J. D., and Mollnes, T. E. (2010) Selective inhibition of TNFalpha or IL-1beta does not affect E. coli-induced inflammation in human whole blood. Mol. Immunol 47, 1774-1782 
44. Gustavsen, A., Nymo, S., Landsem, A., Christiansen, D., Ryan, L., Husebye, H., Lau, C., Pischke, S. E., Lambris, J. D., Espevik, T., and Mollnes, T. E. (2016) Combined Inhibition of Complement and CD14 Attenuates Bacteria-Induced Inflammation in Human Whole Blood More Efficiently Than Antagonizing the Toll-like Receptor 4-MD2 Complex. J Infect Dis 214, 140-150

45. Schaefer, L. (2014) Complexity of danger: the diverse nature of damage-associated molecular patterns. J Biol Chem 289, 35237-35245

46. Lee, C. C., Avalos, A. M., and Ploegh, H. L. (2012) Accessory molecules for Toll-like receptors and their function. Nat Rev Immunol 12, 168-179

47. Di, G. M., and Zanoni, I. (2015) Toll-like receptor co-receptors as master regulators of the immune response. Mol. Immunol 63, 143-152

48. Yang, S., Zhou, M., Chaudry, I. H., and Wang, P. (2002) Novel approach to prevent the transition from the hyperdynamic phase to the hypodynamic phase of sepsis: role of adrenomedullin and adrenomedullin binding protein-1. Ann Surg 236, 625-633

49. Ward, P. A. (2004) The dark side of C5a in sepsis. Nat. Rev. Immunol 4, 133-142

50. Liu, Z. M., Zhu, S. M., Qin, X. J., Cheng, Z. D., Liu, M. Y., Zhang, H. M., and Liu, D. X. (2010) Silencing of C5a receptor gene with siRNA for protection from Gram-negative bacterial lipopolysaccharide-induced vascular permeability. Mol. Immunol

51. Opal, S. M., and van der Poll, T. (2014) Endothelial barrier dysfunction in septic shock. J. Intern. Med 277, 277-293

52. Hajishengallis, G., and Lambris, J. D. (2010) Crosstalk pathways between Toll-like receptors and the complement system. Trends Immunol 31, 154-163

53. Lau, C., Nygard, S., Fure, H., Olstad, O. K., Holden, M., Lappegard, K. T., Brekke, O. L., Espevik, T., Hovig, E., and Mollnes, T. E. (2015) CD14 and complement crosstalk and largely mediate the transcriptional response to Escherichia coli in human whole blood as revealed by DNA microarray. PLoS One 10, e0117261

54. Barratt-Due, A., Pischke, S. E., Nilsson, P. H., Espevik, T., and Mollnes, T. E. (2017) Dual inhibition of complement and Toll-like receptors as a novel approach to treat 
inflammatory diseases-C3 or C5 emerge together with CD14 as promising targets. $J$ Leukoc Biol 101, 193-204

55. Peiretti, F., Alessi, M. C., Henry, M., Anfosso, F., Juhan-Vague, I., and Nalbone, G. (1997) Intracellular calcium mobilization suppresses the TNF-alpha-stimulated synthesis of PAI-1 in human endothelial cells. Indications that calcium acts at a translational level. Arterioscler Thromb Vasc Biol 17, 1550-1560

56. Huber-Lang, M., Barratt-Due, A., Pischke, S. E., Sandanger, O., Nilsson, P. H., Nunn, M. A., Denk, S., Gaus, W., Espevik, T., and Mollnes, T. E. (2014) Double blockade of CD14 and complement C5 abolishes the cytokine storm and improves morbidity and survival in polymicrobial sepsis in mice. J Immunol 192, 5324-5331

57. Lloyd-Jones, K. L., Kelly, M. M., and Kubes, P. (2008) Varying importance of soluble and membrane CD14 in endothelial detection of lipopolysaccharide. J Immunol 181, $1446-1453$

58. Yang, Z., Breider, M. A., Carroll, R. C., Miller, M. S., and Bochsler, P. N. (1996) Soluble CD14 and lipopolysaccharide-binding protein from bovine serum enable bacterial lipopolysaccharide-mediated cytotoxicity and activation of bovine vascular endothelial cells in vitro. J Leukoc Biol 59, 241-247

59. Haziot, A., Rong, G. W., Silver, J., and Goyert, S. M. (1993) Recombinant soluble CD14 mediates the activation of endothelial cells by lipopolysaccharide. $\mathrm{J}$ Immunol $151,1500-1507$ 


\section{Figure Legends}

Figure 1: Effect of pretreatment with anti-CD14 antibody (23G4) on vital signs and survival following $E$. coli sepsis. Time course changes of the effect of anti-CD14 treatment on (A) mean systemic arterial pressure (MSAP), $(B)$ heart rate, $(C)$ respiration, $(D)$ oxygen saturation, and $(E)$ core temperature following $E$. coli challenge. Data are presented as mean \pm SEM. Same time points are compared between LD100 control and LD100+anti-CD14 antibody treated baboons using multiple $t$ tests with correction for multiple comparisons using the Holm-Sidak method. ${ }^{*} p<0.05,{ }^{* *} p<0.01,{ }^{* * * *} p<0.0001$. (F) Kaplan-Meier survival plots of control and anti-CD14 treated baboons after LD100 E. coli challenge. Animals that survived for 168 hours (7 days) were considered permanent survivors. Survival curves were compared using Log-rank (Mantel-Cox) test and showed significantly higher survival in the anti-CD14 treated group $(p=0.0018)$.

Figure 2: Pretreatment of baboons with anti-CD14 antibody reduced markers of capillary leak and complement activation. Time course changes of $(A)$ total plasma protein and (B) plasma albumin in baboons with or without anti-CD14 treatment following $E$. coli challenge. Complement activation markers in plasma (C) C3b, (D) C5a, and (E) terminal complement complex (C5b-9) were evaluated during E. coli sepsis. Data are presented as mean \pm SEM. Same time points are compared between LD100 and LD100+anti-CD14 baboons using multiple $t$ tests followed by Holm-Sidak correction. ${ }^{*} p<0.05,{ }^{* * *} p<0.001$..

Figure 3: Effect of pretreatment of baboons with anti-CD14 antibody on markers of coagulation. Time course dynamics of clotting times: (A) APTT, (B) PT, and hemostatic markers: (C) FXla-AT complex, (D) FVIla-AT complex, (E) Thrombin-antithrombin complex (TAT), (F) APC- $\alpha 1$ antitrypsin complex, and (G) fibrinogen during E. coli sepsis. Data are presented as mean \pm SEM. Same time points are compared between LD100 and 
LD100+anti-CD14 baboons using multiple $t$ tests followed by Holm-Sidak correction. ${ }^{*} p$ $<0.05,{ }^{* *} p<0.01,{ }^{* * *} p<0.001$

Figure 4: Effect of treatment of baboons with anti-CD14 antibody on markers of fibrinolysis. Time course changes of plasma biomarkers: (A) fibrin degradation products (FDP), (B) tissue-type plasminogen activator (tPA), (C) plasminogen activator inhibitor - 1 (PAI-1), (D) plasmin-antiplasmin complex (PAP), (E) D-Dimer, and (F) thrombin activatable fibrinolysis inhibitor (TAFI) were evaluated following $E$. coli challenge with or without antiCD14 treatment. Data are presented as mean \pm SEM. Same time points are compared between LD100 and LD100+anti-CD14 baboons using multiple t tests followed by HolmSidak correction. ${ }^{*} p<0.05,{ }^{* *} p<0.01,{ }^{* * *} p<0.001,{ }^{* * * *} p<0.0001$.

Figure 5: Effect of treatment of baboons with anti-CD14 antibody on circulating proand anti-inflammatory cytokines. Time course evaluation of cytokines in plasma: (A) TNF, (B) IFN- $\gamma,(C)$ IL-1RA, (D) IL-1 $\beta,(E)$ IL-8, (F) MCP-1, (G) IL-17a, (H) GM-CSF, (I) IL-6, and (J) IL-10 during E. coli sepsis with or without anti-CD14 treatment. Data are presented as mean \pm SEM. Same time points are compared between LD100 and LD100+anti-CD14 baboons using multiple $t$ tests followed by Holm-Sidak correction. ${ }^{*} p<0.05,{ }^{* *} p<0.01$, ${ }^{* * * *} p<0.0001$.

Figure 6: Effect of treatment of baboons with anti-CD14 antibody on blood cells count and myeloperoxidase activity. (A) White blood cells (WBC), (B) Myeloperoxidase activity (MPO), (C) Platelets, and (D) red blood cells (RBC) counts were evaluated in plasma of baboons with or without anti-CD14 treatment following E. coli challenge. Data are presented as mean \pm SEM. Same time points are compared between LD100 and LD100+anti-CD14 baboons using multiple t tests followed by Holm-Sidak correction. ${ }^{*} p<0.05$, ${ }^{* * * *} p<0.0001$. 
Figure 7: Effect of treatment of baboons with anti-CD14 antibody on markers of cell death. (A) Citrullinated (Cit) H3, (B) Nucleosomes, and (C) HMGB1 were evaluated in plasma of CD14 treated or untreated baboons following E. coli challenge. Data are presented as mean \pm SEM. Same time points are compared between LD100 and LD100+anti-CD14 baboons using multiple $t$ tests followed by Holm-Sidak correction. ${ }^{*} p<0.05$, ${ }^{* * * *} p<0.0001$.

Figure 8: Effect of treatment of baboons with anti-CD14 antibody on biomarkers of organ function. Time course changes of organ function markers (A) Alanine aminotransferase (ALT), (B) creatinine and $(C)$ lactate in plasma of baboons with or without anti-CD14 treatment during E. coli sepsis. Data are presented as mean \pm SEM. Same time points are compared between LD100 and LD100+anti-CD14 baboons using multiple t tests followed by Holm-Sidak correction. ${ }^{*} p<0.05,{ }^{* * * *} p<0.0001$.

Figure 9: Effect of treatment of baboons with anti-CD14 antibody on histological changes of vital organs. Organs were collected at the time of necropsy, sections were stained with H\&E and semi-quantitative evaluation of the pathological features of (A) Kidney, (B) Spleen, (C) Lung, (D) Liver, and (E) Adrenal was performed. The pathologist was blinded as to the experimental condition. The severity score was assigned from 0 to 4 , with 0 being normal and 4 being severe. Data are presented as mean \pm SEM. Same pathological parameters are compared between LD100 and LD100+anti-CD14 baboons using multiple $t$ tests followed by Holm-Sidak correction. ${ }^{*} p<0.05,{ }^{* *} p<0.01,{ }^{* * *} p<0.001$.

Figure 10: Effect of treatment of baboons with anti-CD14 antibody on adrenals histopathology. Representative images of adrenals sections stained with H\&E from baboons treated ( $A$ and $B$ ) or not treated $(C$ and $D)$ with anti-CD14 antibody during $E$. coli sepsis. (A), (B) Treated animals adrenals display normal morphology with occasional inflammatory cells infiltration (B, arrow). (C), (D) Control animals adrenals display severe hemorrhage $\left({ }^{*}\right)$, necrosis (\#), inflammatory cells infiltration (solid arrow) and congestion 
(empty arrow). (A) and (C), low magnification (bars: $100 \mu \mathrm{m}) ;(B)$ and (D), high magnification (bars: $100 \mu \mathrm{m}$ ).

Figure 11: Effect of treatment of baboons with anti-CD14 antibody on circulating LPS, LBP, sCD14 and bacteria colony counts. Time course of circulating (A) LPS, (B) LPS binding protein (LBP), and (C) soluble CD14 (sCD14) in plasma of anti-CD14 treated or untreated baboons during E. coli sepsis. (D) Bacteria in the blood were determined by counting the colony forming units (CFU) on agar plates. Data are presented as mean \pm SEM. Same time points are compared between LD100 and LD100+anti-CD14 baboons using multiple t tests followed by Holm-Sidak correction. ${ }^{*} p<0.05,{ }^{* *} p<0.01,{ }^{* * *} p<0.001,{ }^{* * * *} p$ $<0.0001$ 


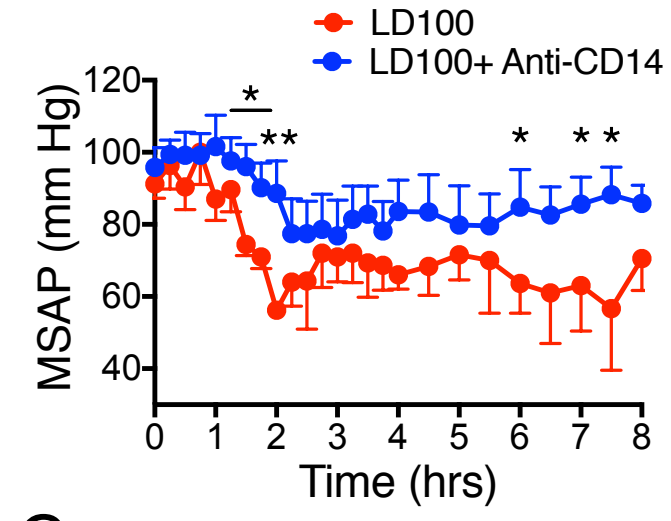

B

C

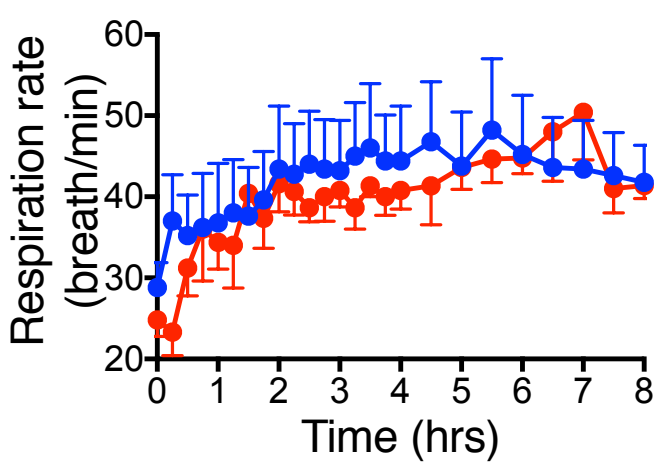

D
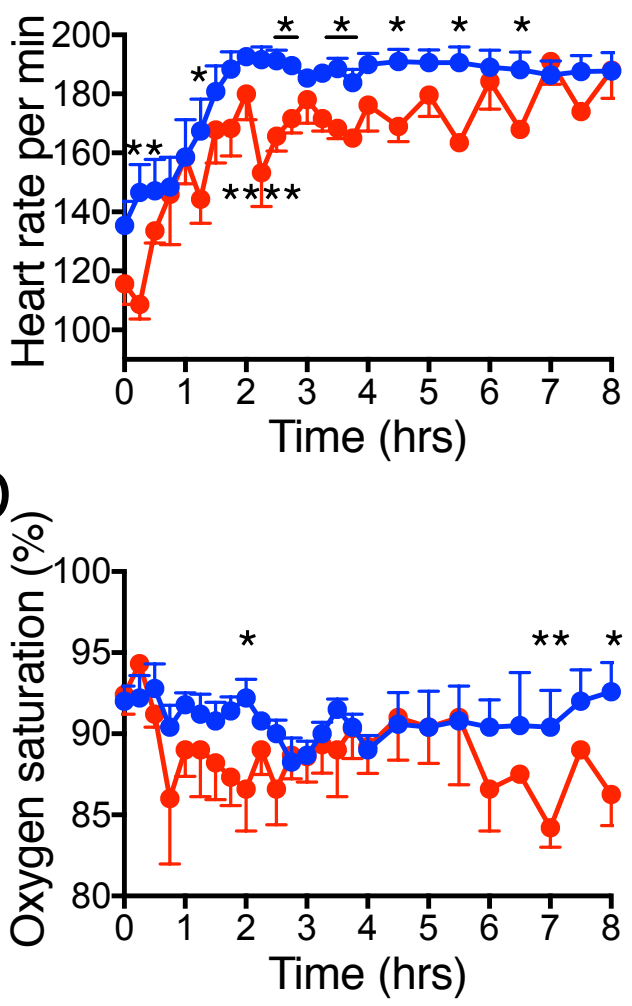

E
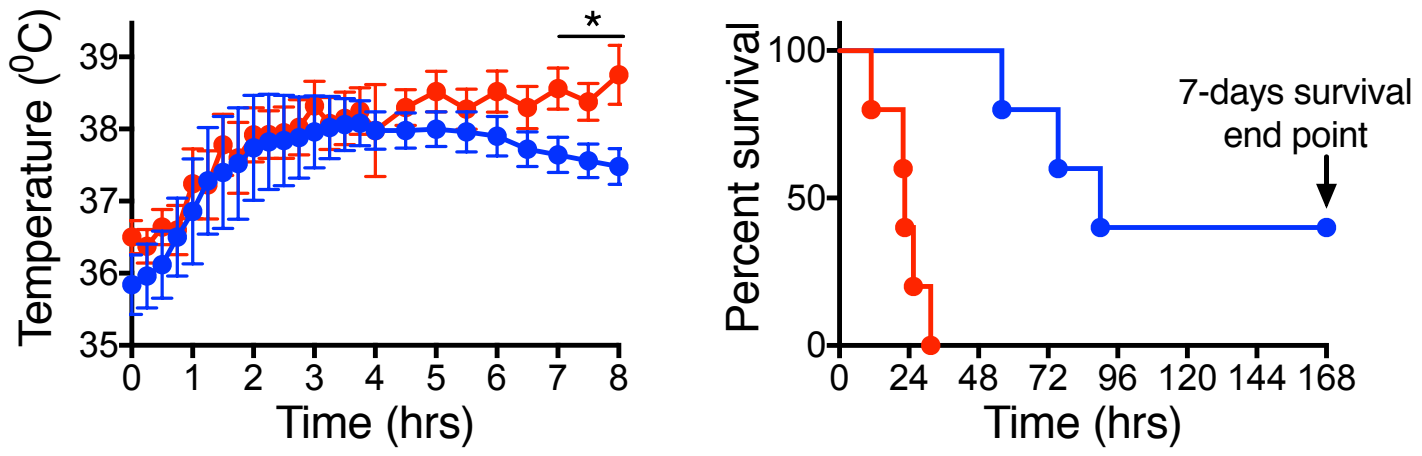

Figure 1 

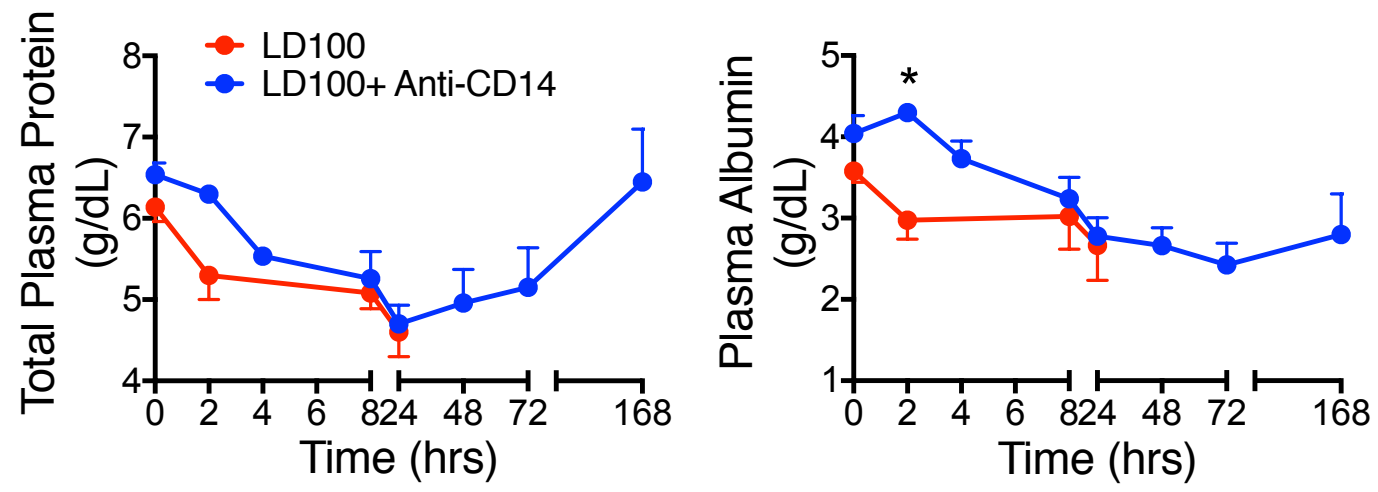

0
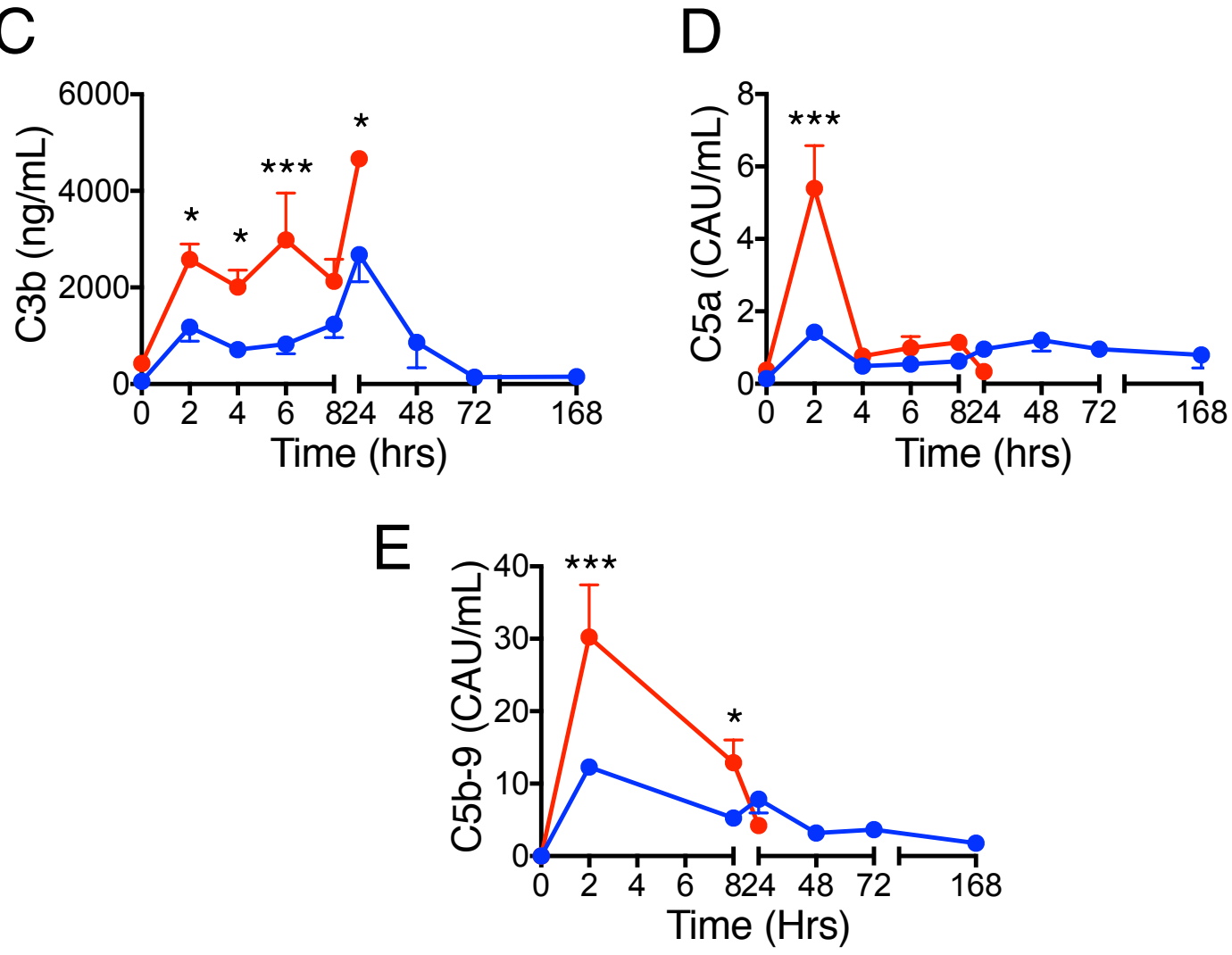

Figure 2 
A

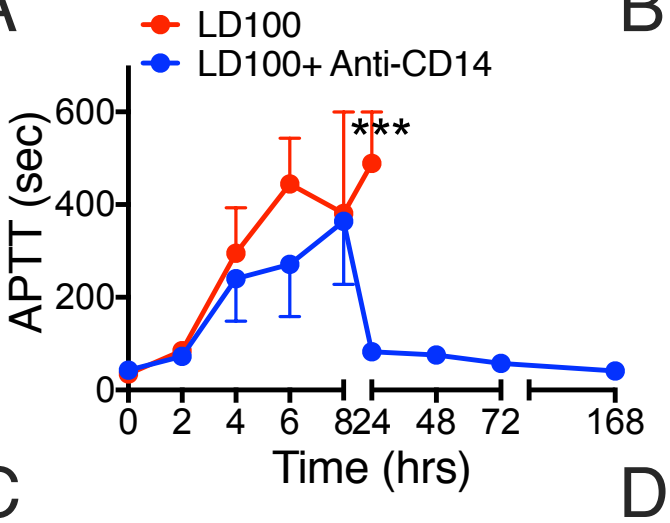

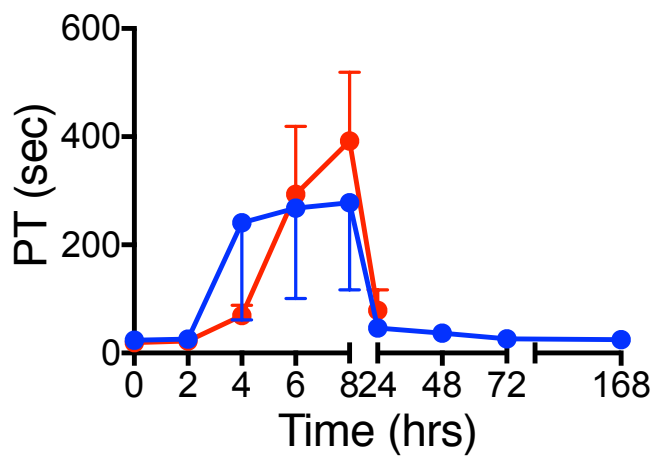

क

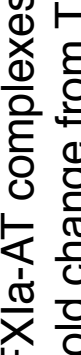
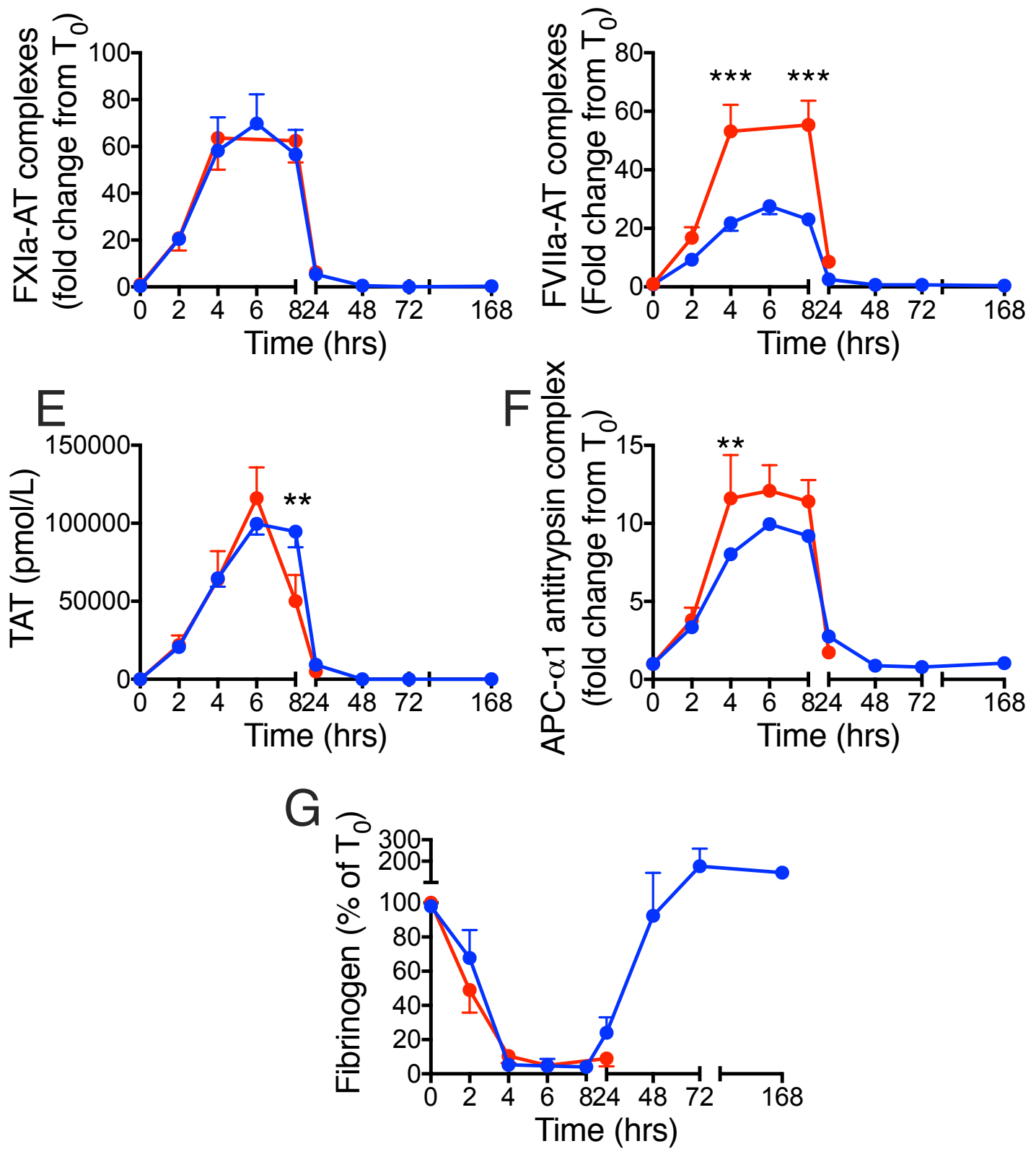

Figure 3 
A
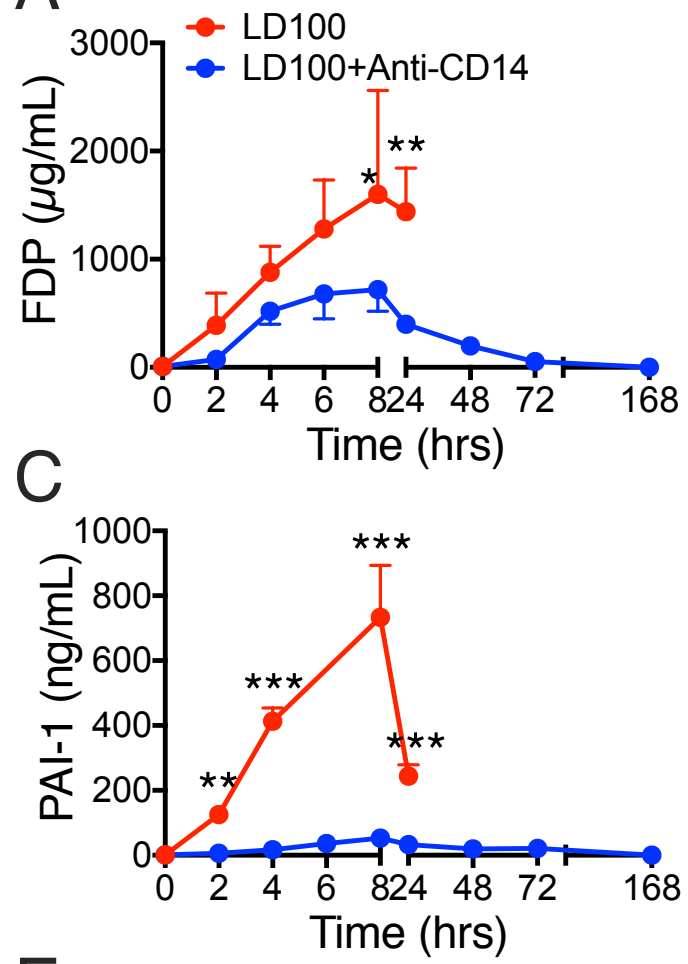

E

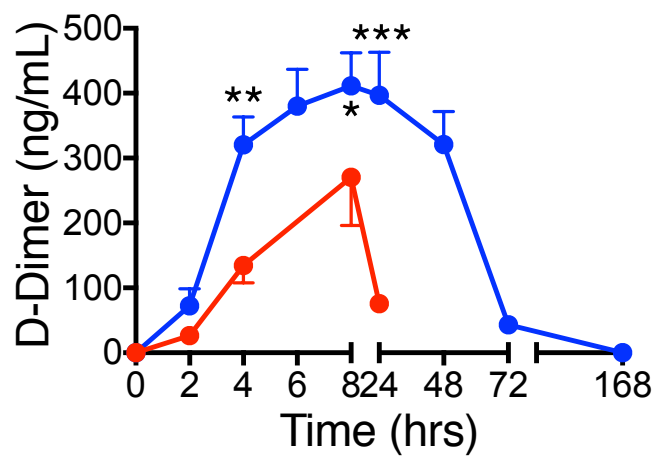

B
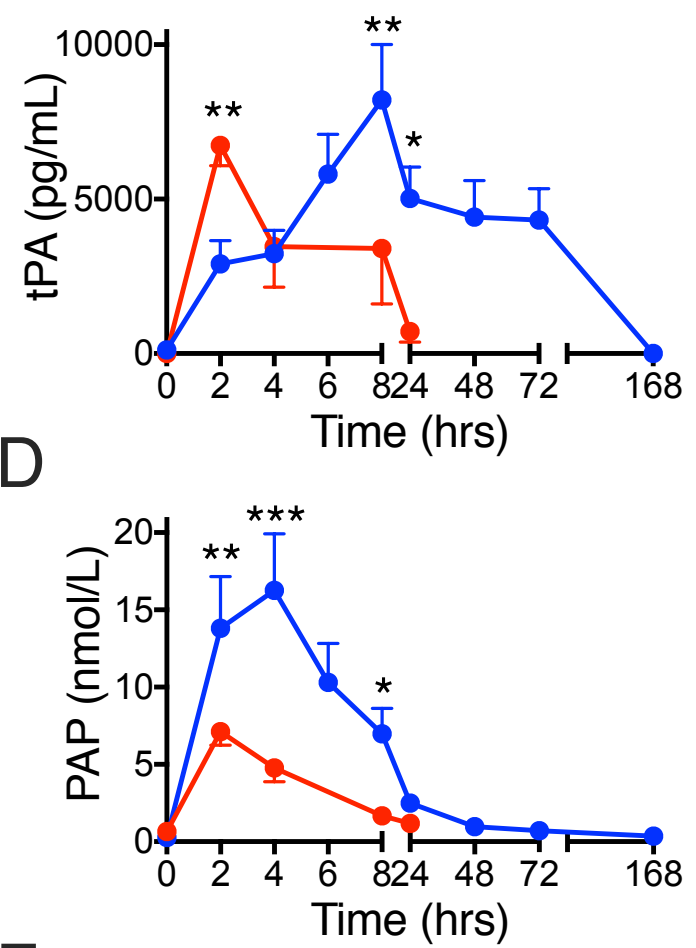

F

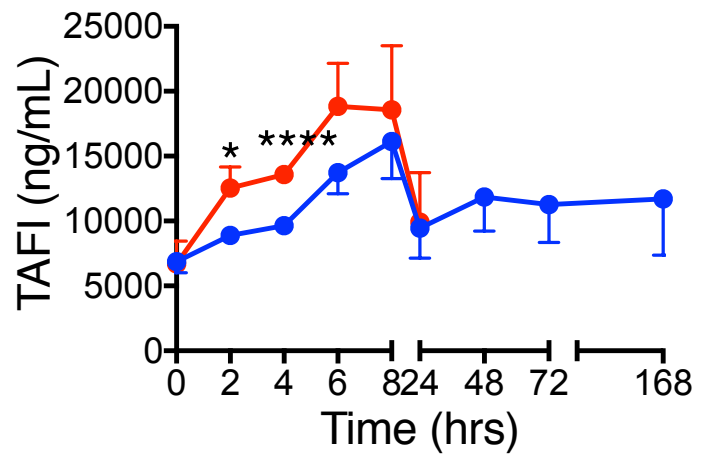

Figure 4 

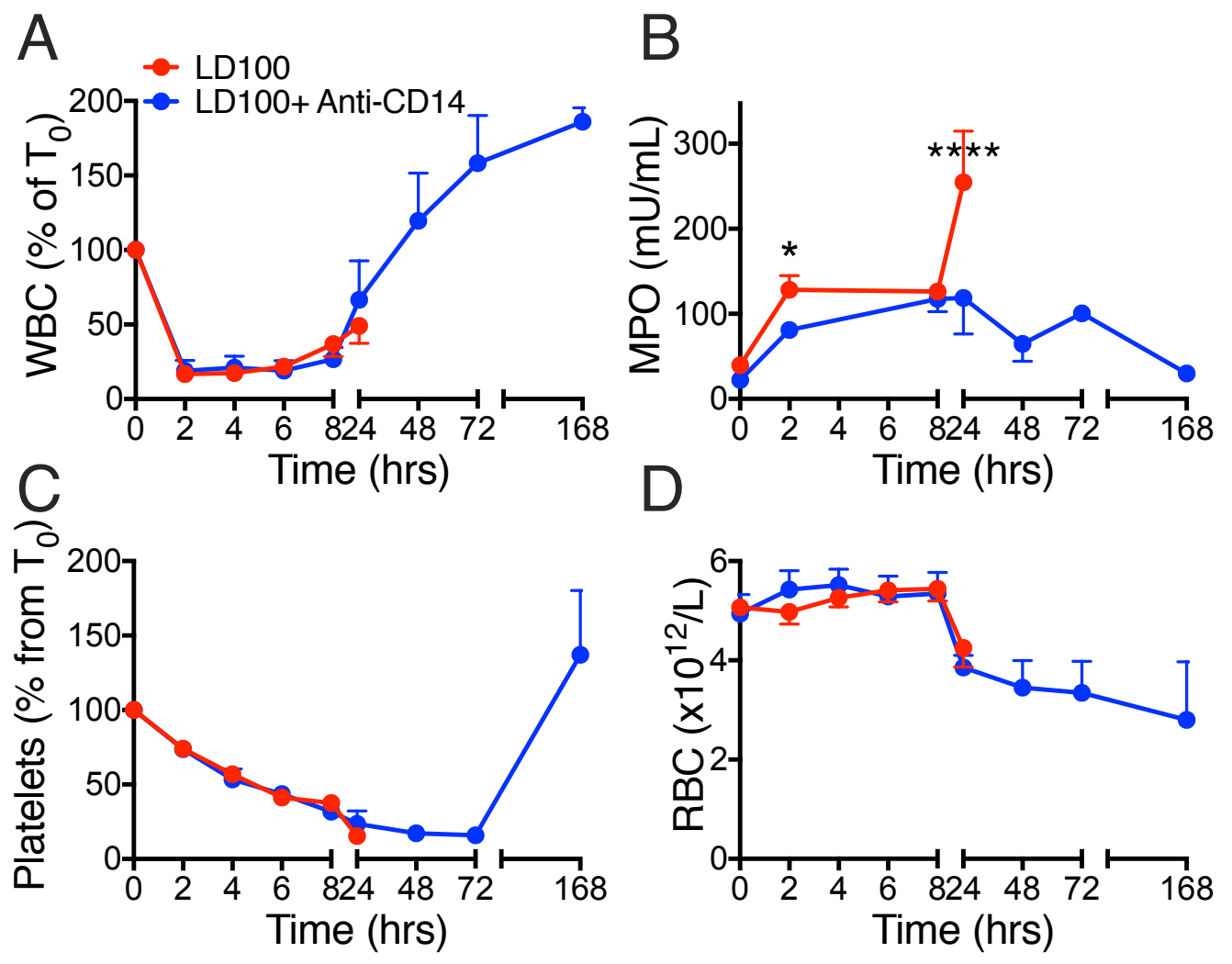

Figure 6 


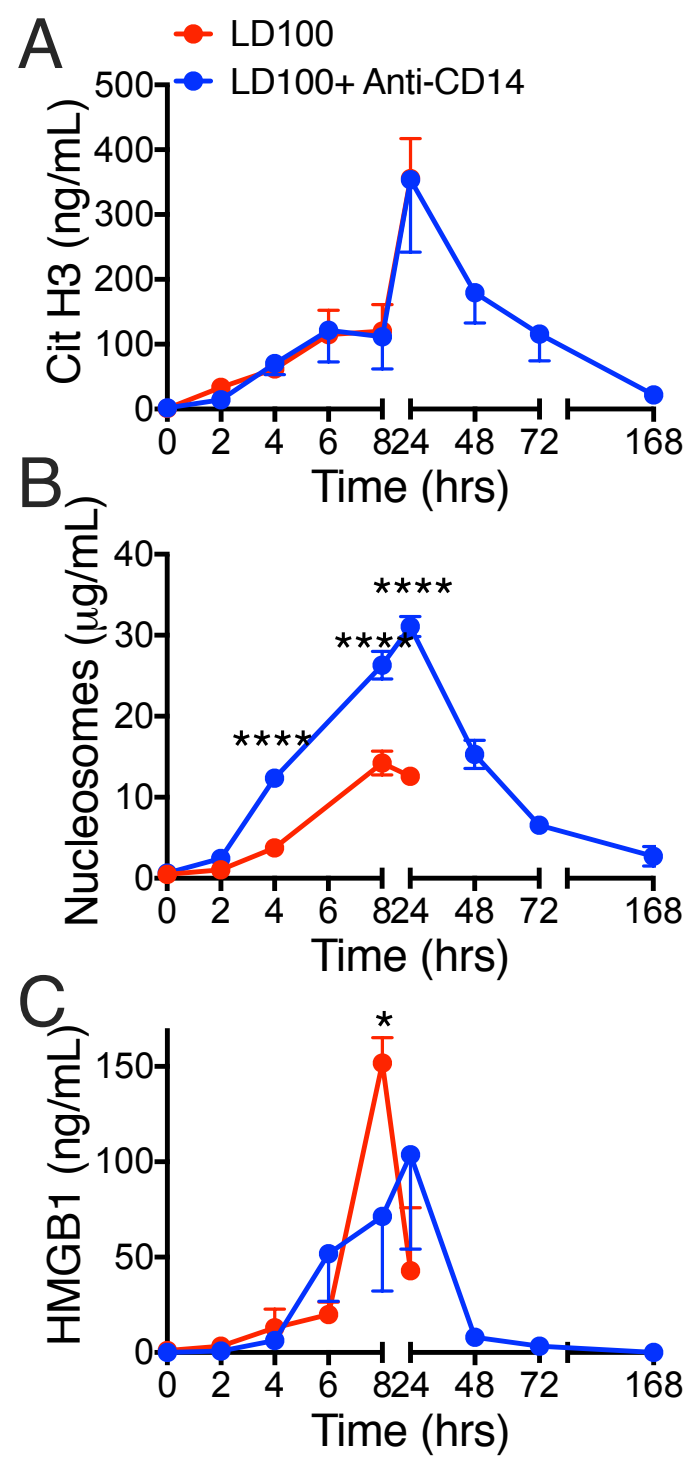

Figure 7 


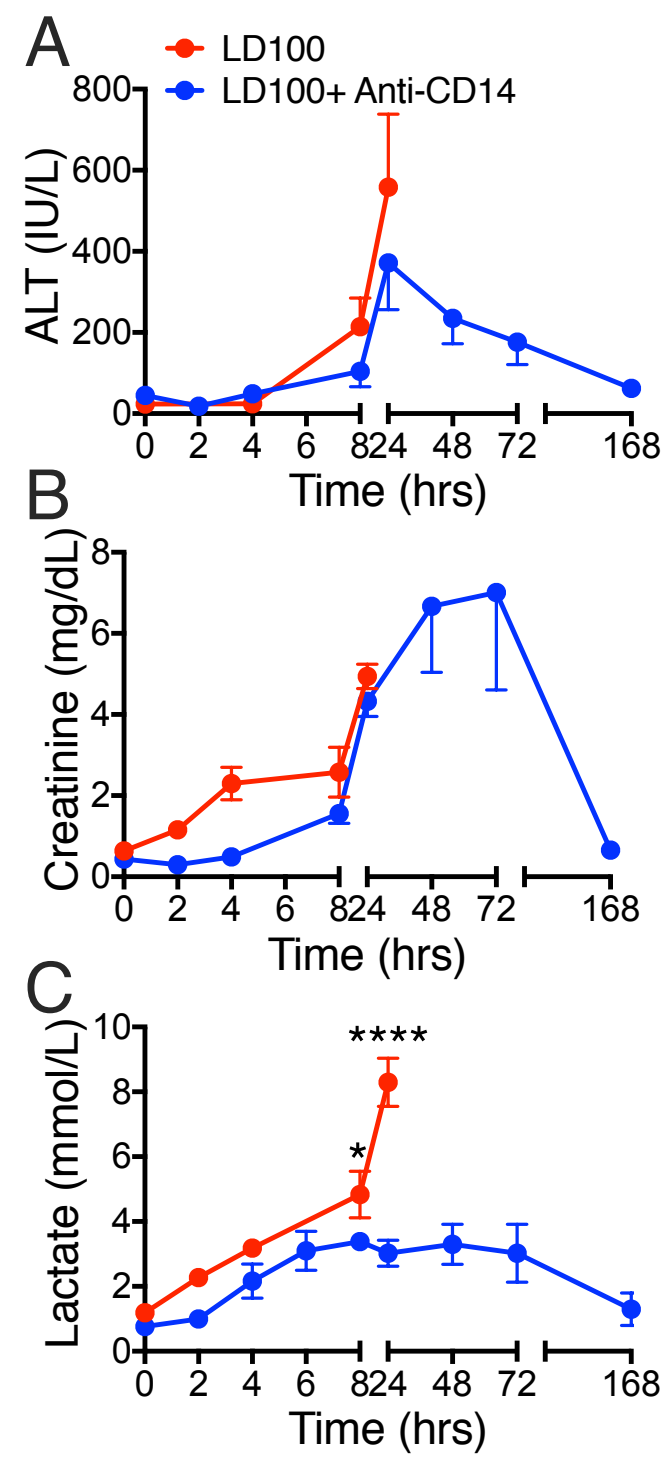

Figure 8 
A Medullary $\begin{gathered}\text { tubular necrosis } \\ \text { Glomerular }\end{gathered}-\square=\begin{aligned} & \text { LD100 } \\ & \text { LD100+ Anti-CD14 }\end{aligned}$ microthrombosis

Granular cast formation

Cortical

tubular necrosis Cortical hemorrhage

Corticomedullary congestion

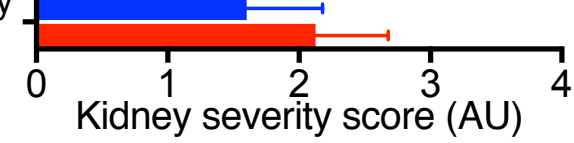

B

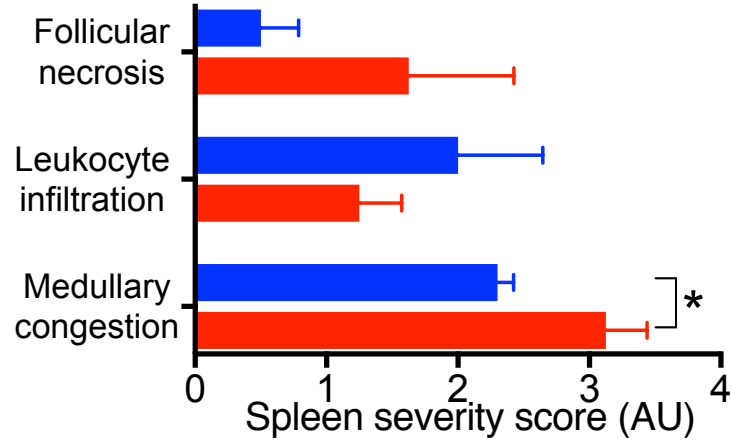

C
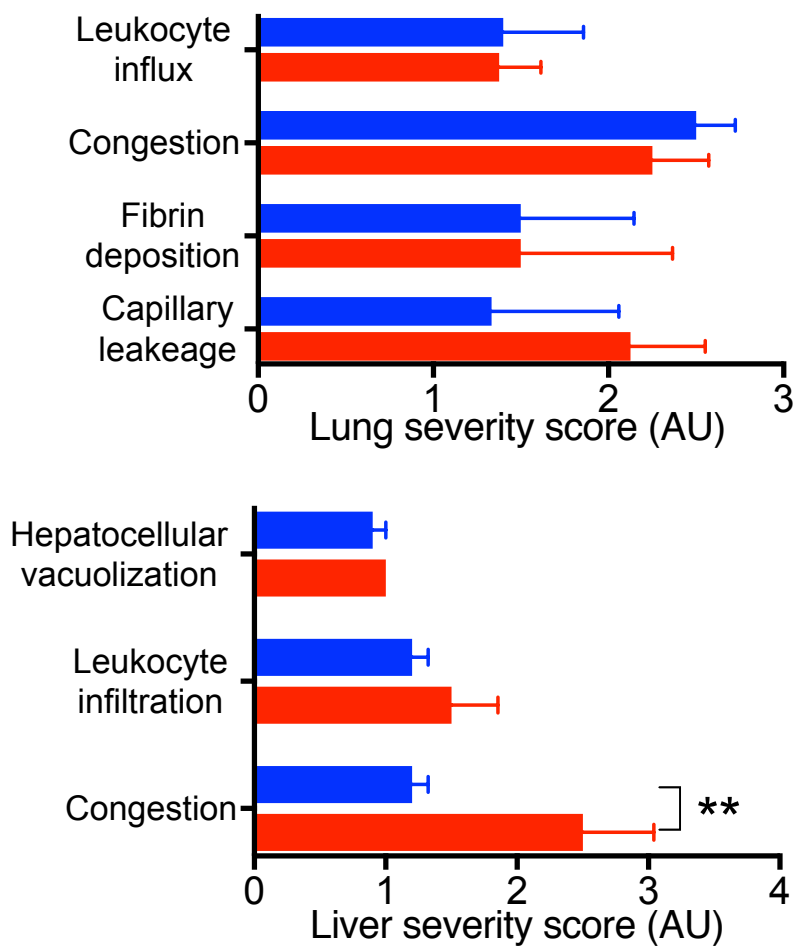

E Medullary congestion Microthrombosis Leukocyte infiltration

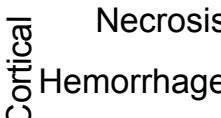

Congestion

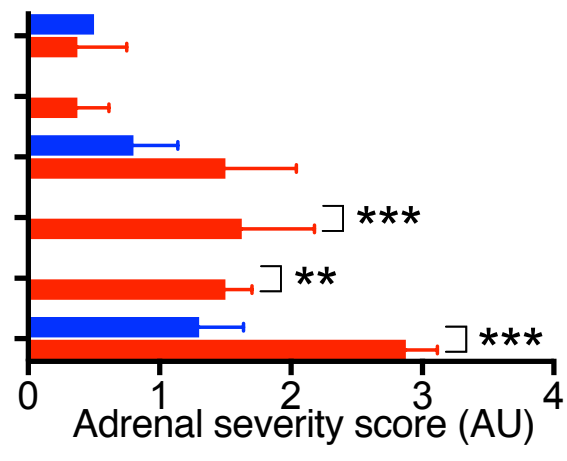




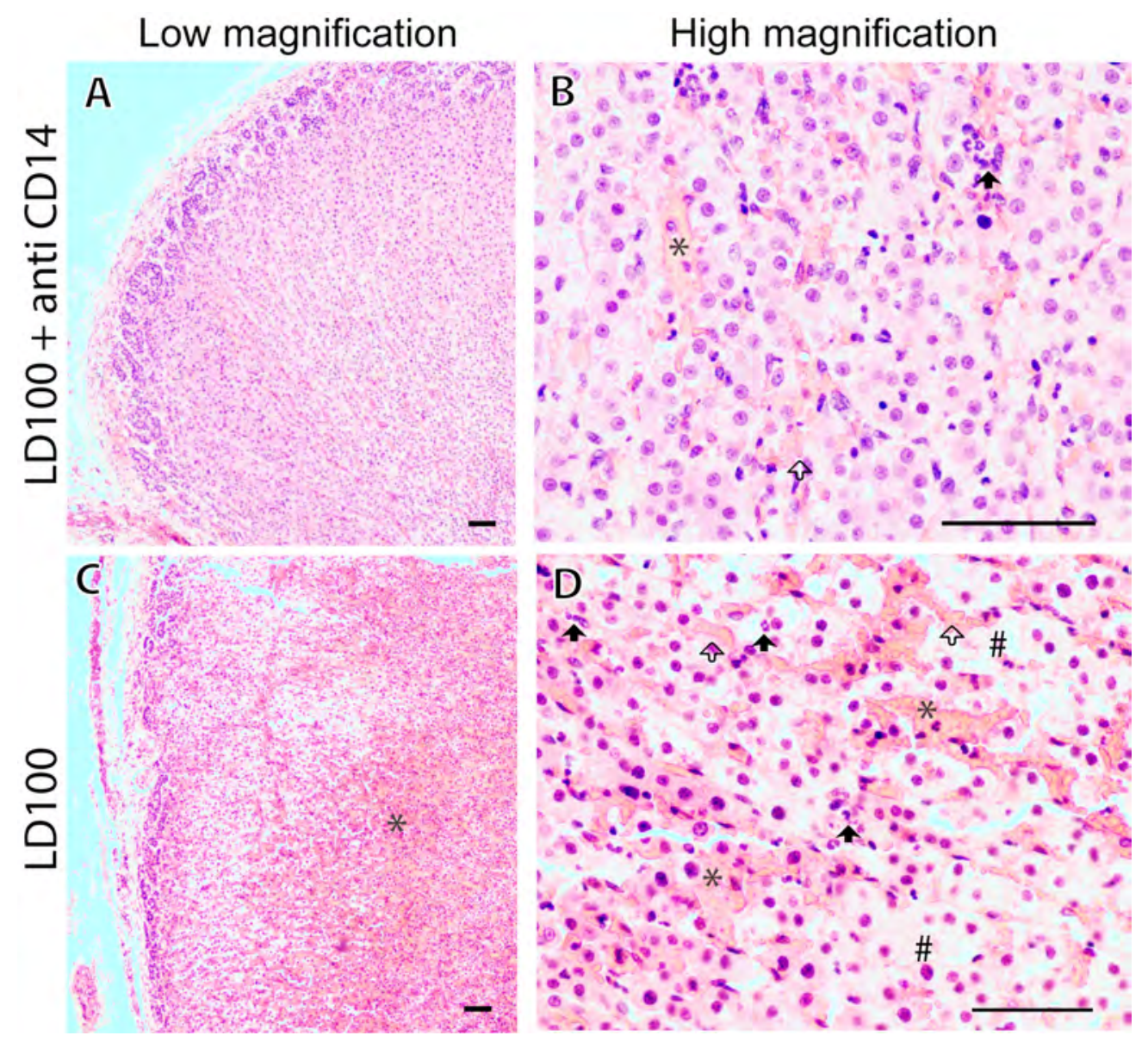

Figure 10 
A

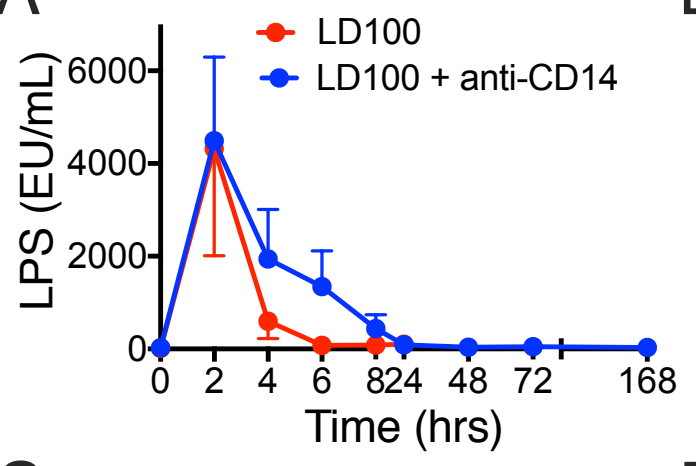

B

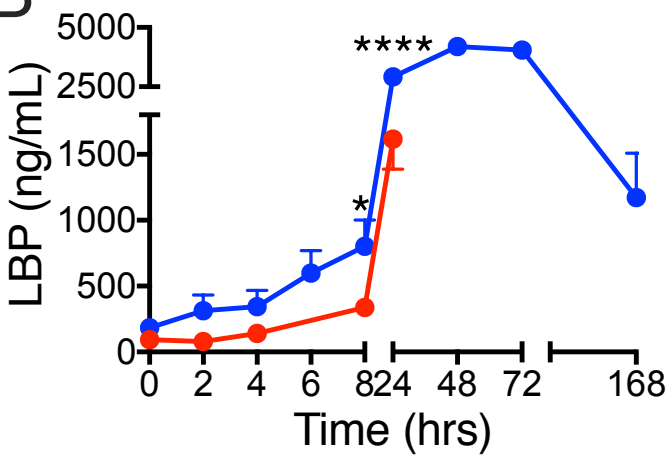

C
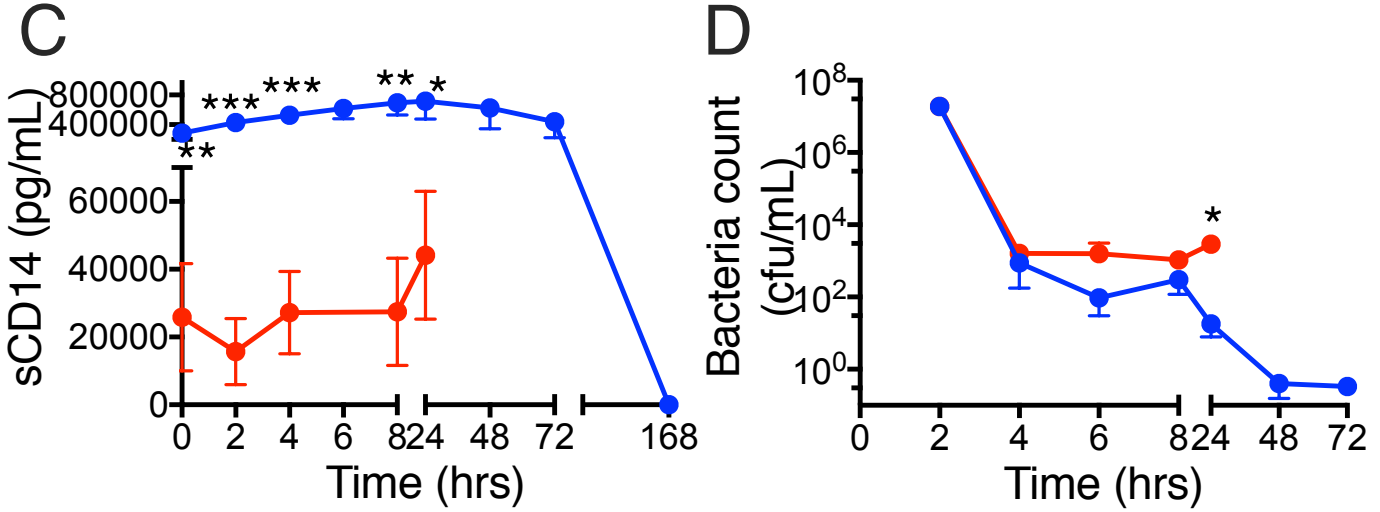

\section{Figure 11}




\section{Supplementary Information for:}

CD14 inhibition improves survival and attenuates cardiopulmonary dysfunction and thrombo-inflammation in a non-human primate model of Escherichia coli sepsis

Ravi S. Keshari, Robert Silasi, Narcis I. Popescu, Hala Chaaban, Cristina Lupu, Tom E. Mollnes, Florea Lupu

Corresponding author: Florea Lupu,

E-mail: florea-lupu@omrf.org

This PDF file includes:

Figs. S1 to S3 


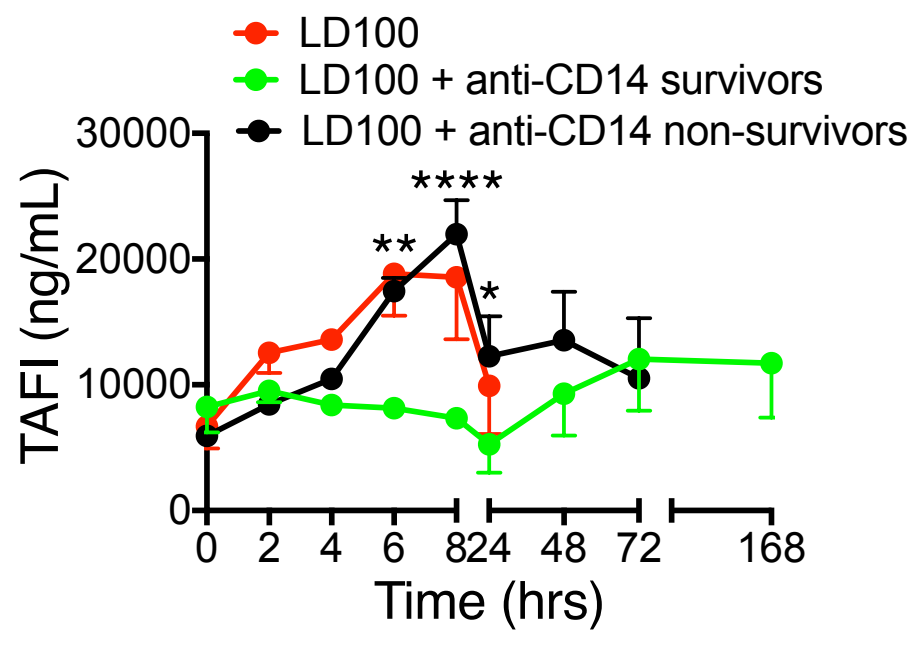

Figure S1. TAFI levels in plasma from LD100 controls and anti-CD14 antibody treated survivors and non-survivor baboons. TAFI was measured in the plasma of LD100, LD100+ anti-CD14 survivor, and LD100 + anti-CD14 non-survivor baboons. Data are presented as mean \pm SEM. Same time points are compared between survivors and non-survivors within the LD100+anti-CD14 treated baboons using multiple t tests followed by Holm-Sidak correction. ${ }^{*} p<0.05,{ }^{* *} p<0.01 ;{ }^{* * * *} p<0.0001$. 


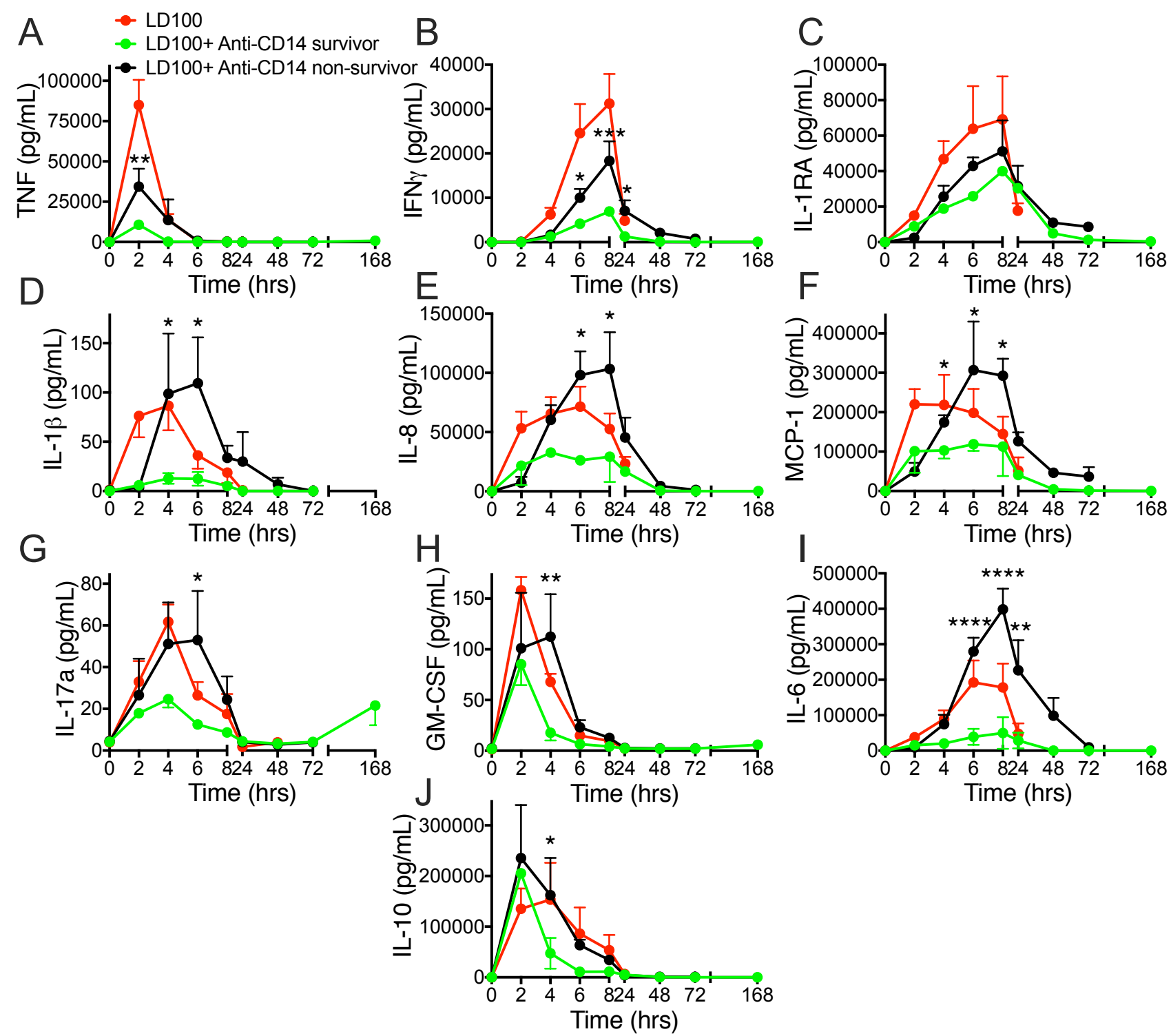

Figure S2: Pro- and anti-inflammatory cytokines in LD100 controls and anti-CD14 antibody treated survivors and non-survivor baboons. Cytokines were measured in the plasma of LD100, LD100+ anti-CD14 survivor, and LD100+ anti-CD14 non-survivor baboons. (A) TNF, (B) IFN- $\gamma$, (C) IL-1RA, (D) IL-1 $\beta$, (E) IL-8, (F) MCP-1, (G) IL-17a, (H) GM-CSF, (I) IL-6, and $(\mathrm{J}) \mathrm{IL}-10$. Data are presented as mean \pm SEM. Same time points are compared between survivors and non-survivors within the LD100+anti-CD14 treated baboons using multiple t tests followed by Holm-Sidak correction. ${ }^{*} p<0.05,{ }^{* *} p<0.01,{ }^{* * *} p<0.001,{ }^{* * *} p<0.0001$. 

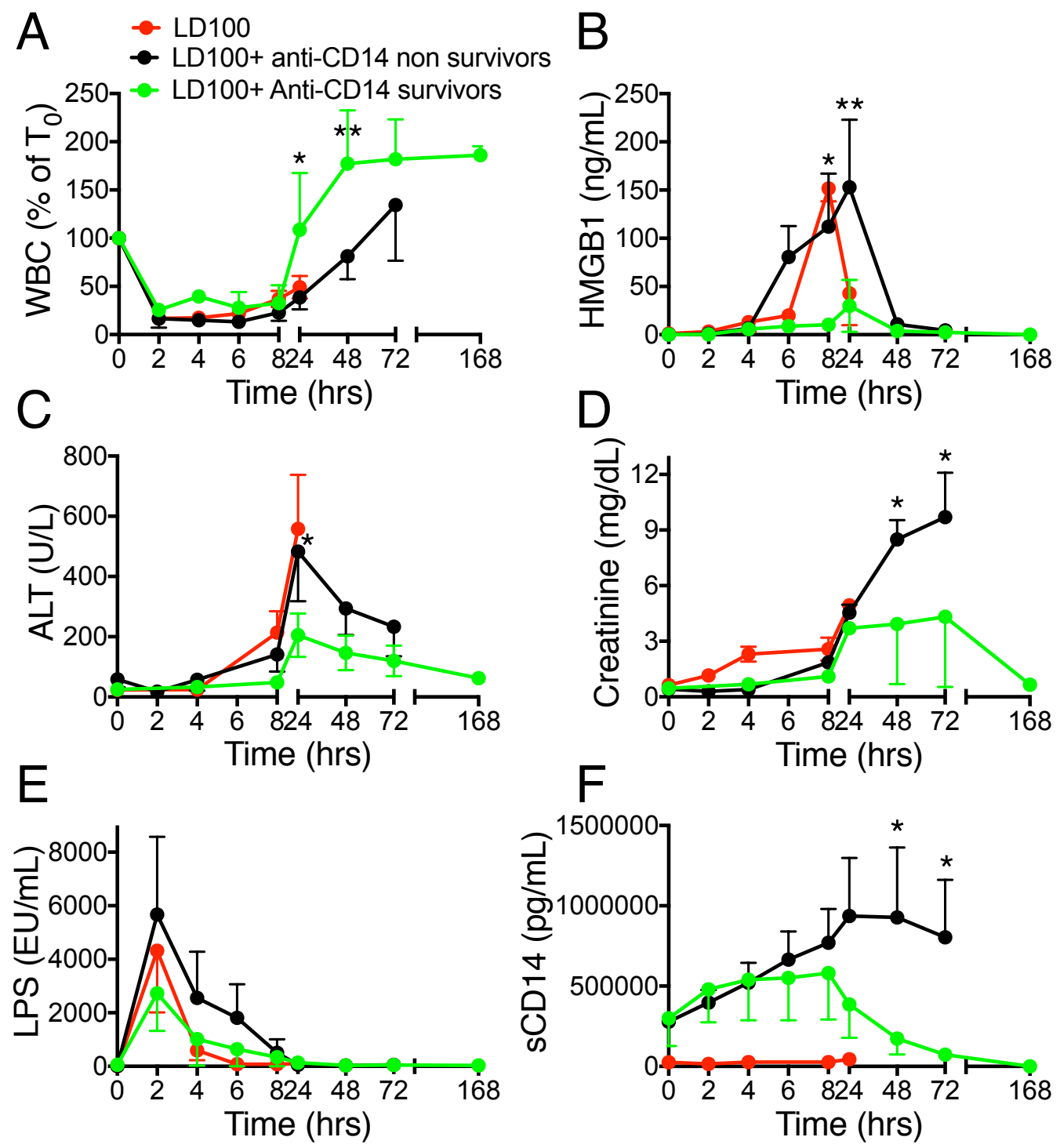

Figure S3. Effect of treatment with anti-CD14 antibody on various plasma markers in LD100 controls and anti-CD14 antibody treated survivors and non-survivor baboons.

Time course changes in (A) white blood cells (WBC), (B) HMGB1, (C) ALT, (D) Creatinine, (E) LPS and (F) sCD14 levels were measured in the plasma of LD100, LD100+ anti-CD14 survivor, and LD100+ anti-CD14 non-survivor baboons. Data are presented as mean \pm SEM. Same time points are compared between survivors and non-survivors within the LD100+anti-CD14 treated baboons using multiple $t$ tests followed by Holm-Sidak correction. ${ }^{*} p<0.05,{ }^{* *} p<0.01$. 